\title{
Review
}

\section{Recent Advances in Catalytic [3,3]-Sigmatropic Rearrangements}

\author{
Huijin Lee, Ki Tae Kim*(D), Min Kim*(D) and Cheoljae Kim*(D)
}

Department of Chemistry, Chungbuk National University, Cheonju 28644, Korea; 98_0116@chungbuk.ac.kr

* Correspondence: ktkim@chungbuk.ac.kr (K.T.K.); minkim@chungbuk.ac.kr (M.K.);

iamckim@chungbuk.ac.kr (C.K.); Tel.: +82-43-261-2286 (K.T.K.); +82-43-261-2283 (M.K.); +82-43-261-2305 (C.K.)

check for

updates

Citation: Lee, H.; Kim, K.T.; Kim, M.; Kim, C. Recent Advances in Catalytic [3,3]-Sigmatropic Rearrangements. Catalysts 2022, 12, 227. https:/ / doi.org/10.3390/catal12020227

Academic Editor: Kotohiro Nomura

Received: 10 January 2022

Accepted: 14 February 2022

Published: 16 February 2022

Publisher's Note: MDPI stays neutral with regard to jurisdictional claims in published maps and institutional affiliations.

Copyright: (c) 2022 by the authors. Licensee MDPI, Basel, Switzerland. This article is an open access article distributed under the terms and conditions of the Creative Commons Attribution (CC BY) license (https:// creativecommons.org/licenses/by/ $4.0 /)$.

\begin{abstract}
Carbon-carbon bond formation by [3,3]-sigmatropic rearrangement is a fundamental and powerful method that has been used to build organic molecules for a long time. Initially, Claisen and Cope rearrangements proceeded at high temperatures with limited scopes. By introducing catalytic systems, highly functionalized substrates have become accessible for forming complex structures under mild conditions, and asymmetric synthesis can be achieved by using chiral catalytic systems. This review describes recent breakthroughs in catalytic [3,3]-sigmatropic rearrangements since 2016. Detailed reaction mechanisms are discussed to enable an understanding of the reactivity and selectivity of the reactions. Finally, this review is inspires the development of new cascade reaction pathways employing catalytic [3,3]-sigmatropic rearrangement as related methodologies for the synthesis of complex functional molecules.
\end{abstract}

Keywords: Claisen rearrangement; Cope rearrangement; [3,3]-sigmatropic rearrangement; C-C bond formation; catalysis; transition metal; organocatalyst

\section{Introduction}

Claisen rearrangement was first introduced by L. Claisen in 1912. The initial reaction involved the thermal [3,3]-sigmatropic rearrangement of allyl vinyl ether to $\gamma, \delta$-unsaturated carbonyl compounds [1]. As a useful method of forming carbon-carbon bonds, numerous related reactions have been developed to achieve enhanced reactivity as well as to construct natural products. The substrate scope has been expanded from oxygen-containing molecules to nitrogen- and sulfur-containing congeners, where alkenes as well as alkynes and allenes are used for various transformations [2-5].

Cope rearrangement also involves [3,3]-sigmatropic rearrangement, and is used to form new carbon-carbon bonds via the thermal pseudocyclic reaction of hexa-1,5-dienes [6,7]. Since the first discovery by A. C. Cope in 1940 [8], Cope rearrangement, including the reaction with hetero-analogues, has been extensively studied for application in synthesis, as well as from the theoretical perspective [9-11].

Both representative [3,3]-sigmatropic rearrangements have remained powerful tools in organic synthesis for a long time, and a variety of catalytic versions of these rearrangement reactions were recently developed to achieve the highly reactive and enantioselective synthesis of functionalized molecules by overcoming the limits of the common thermal pathway [12-15]. The combination of transition metals and chiral ligand systems enables the challenging asymmetric synthesis of chiral quaternary carbon-carbon centers, where the highly optically pure corresponding products were obtained in excellent yields. To avoid the drawbacks of unsustainability and economic issues associated with heavy metals, organocatalytic versions of these reactions were actively studied.

In this review, we summarize the developments in the catalytic Claisen and Cope rearrangements since 2016. We describe the detailed mechanism of transition metal-mediated reactions in order to provide deeper understanding of the specific reactivity of metals as well as the regio- and stereoselective pathways. Not only the first-row transition metals, but also the second-row transition metals and lanthanides are reviewed as metal catalysts, 
along with their reactivity, including cascade reactions. Organocatalytic versions of the reactions, which proceed via various catalytic pathways, such as Brønsted acid catalysis, Brønsted base catalysis, Lewis base catalysis, and Lewis acid catalysis, are also described.

\section{Catalytic Claisen Rearrangement}

\subsection{Transition Metal Catalyzed Claisen Rearrangement}

In the Claisen rearrangement, Lewis acid metal catalysts promote the reaction by coordinating to the oxygen atom of the substrates. These catalysts enable the chiral products and promote the formation of chiral carbon-carbon bonds with excellent stereoselectivity. Among various transition metals, $\mathrm{Ni}$ and $\mathrm{Cu}$ species have recently produced big advances in this area.

Feng and colleagues recently developed several enantioselective Claisen rearrangement using chiral $\mathrm{Ni}$ (II) catalysts to generate all-carbon quaternary stereocenters (Scheme 1). In 2016, they achieved the kinetic resolution of racemic propargyl vinyl ethers by asymmetric propargyl Claisen rearrangement in the presence of $\mathrm{Ni}$ (II) species and the chiral $N, N^{\prime}$-dioxide ligand L1 (Scheme 1a) [16]. In general, propargyl vinyl ether could be converted into an allene by Claisen rearrangement. By exploiting kinetic resolution, the racemic phosphonate-substituted substrate $\mathbf{1}$ provided the highly enantio-enriched allene $\mathbf{2}$ in high yield from the corresponding stereoisomer $\mathbf{1}$ in the presence of a chiral catalyst, and the unreacted stereoisomer form of $\mathbf{1}$ was also isolated in high yield with high optical purity. With the achiral single isomer $1\left(\mathrm{R}^{1}=\mathrm{H}, \mathrm{R}^{2}=n \mathrm{Pr}, \mathrm{R}^{3}=\mathrm{Me}, \mathrm{R}^{4}=\right.$ phenyl), the reaction produced the allene 2 with $95 \%$ ee in $87 \%$ yield.

(a) $\mathrm{Ni}(\mathrm{II})$-catalyzed asymmetric propargyl Claisen rearrangement with kinetic resolution

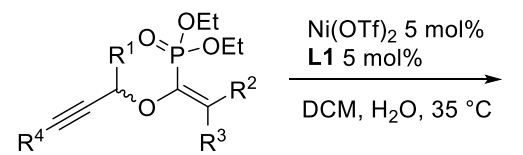

$( \pm)-1$

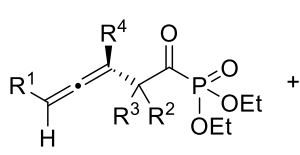

2

up to $48 \%$ yield up to $98 \%$ ee

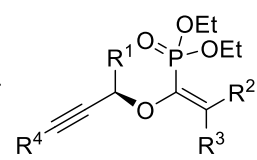

(S)-1

up to $48 \%$ yield up to $99 \%$ ee

(b) $\mathrm{Ni}(\mathrm{II})$-catalyzed asymmetric Claisen rearrangement of allenylmethyl vinyl ethers

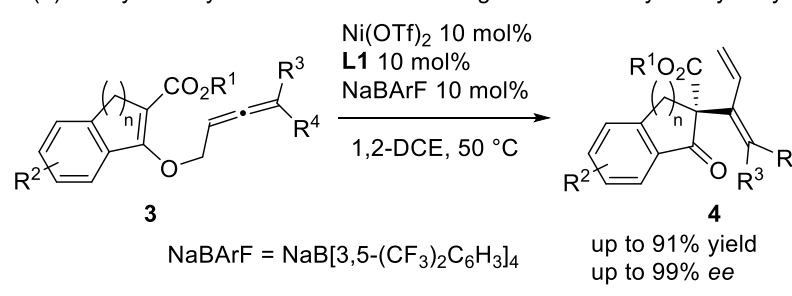

(c) $\mathrm{Ni}(\mathrm{II})$-catalyzed asymmetric Claisen rearrangement of allyl furyl ethers
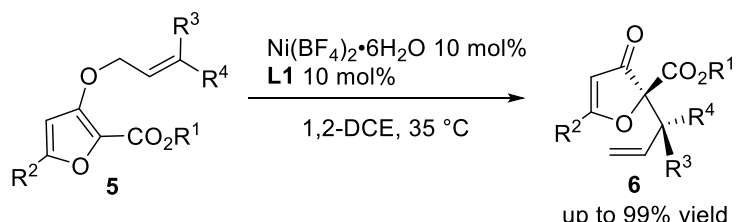

up to $99 \%$ yield up to $99 \%$ e up to $19: 1 \mathrm{dr}$

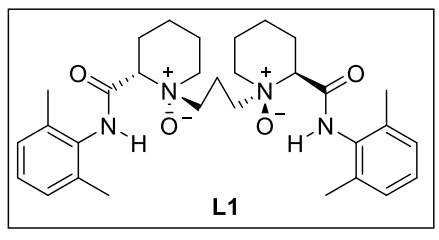

Scheme 1. Ni(II)-catalyzed asymmetric Claisen rearrangement reactions.

In the same year, an asymmetric allenyl Claisen rearrangement was developed by using the same Ni catalyst and chiral ligand system (Scheme 1b) [17]. Allenylmethyl vinyl ethers 3 were converted into 1,3-dienyl substituted compound 4 with a chiral allcarbon quaternary center. This study represents the first example of the enantioselective rearrangement of allenylmethyl vinyl ethers, as well as diastereoselective reactions using a chiral auxiliary. In this reaction, a catalytic amount of $\mathrm{NaBArF}$ improved the reaction yield by increasing the catalytic turnover while suppressing the binding of the metal catalyst to 
the product through the noncoordinating counter-anion. With different alkyl substituents containing allene $3(\mathrm{R} 3 \neq \mathrm{R} 4)$, both $E$ - and $Z$-isomers were obtained with $99 \%$ ee, but the $E / Z$ ratio was only $2: 3$.

In 2018, the catalytic asymmetric Claisen rearrangement of allyl furyl ethers 5 was developed to produce the chiral $\gamma, \delta$-unsaturated carbonyl compounds 6 (Scheme 1c) [18]. By controlling the chirality of the ligand and olefin geometry, all possible stereochemistries could be generated at the adjacent two quaternary carbon centers. This approach is directly applicable in the synthesis of hyperolactone natural products and their epimers. Figure 1 illustrates the stereoselectivity of the reaction based on the catalyst and olefin structure. The chiral catalyst binds to the oxygen of the ether and carbonyl group of the substrate 5a. The $R e$-facial approach provides the favored geometry for the [3,3]-sigmatropic rearrangement to afford enantioselectivity at the $\alpha$-position, whereas the stereochemistry at the $\beta$-position is derived from the olefin structure.
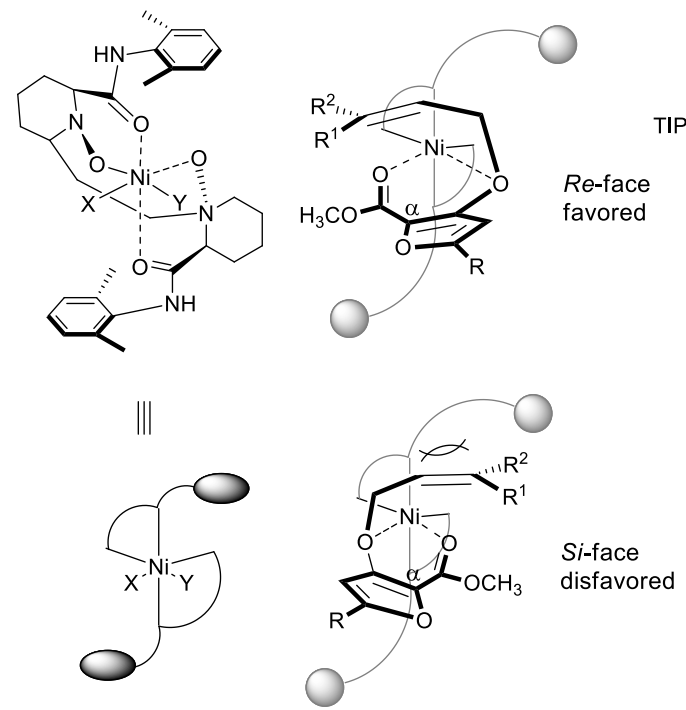

$E$

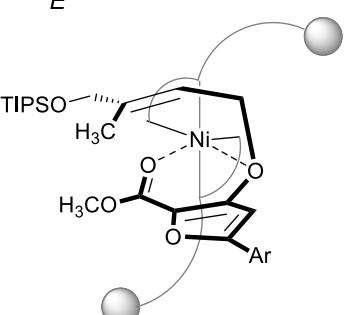

$5 \mathbf{a}\left(\mathrm{Ar}=\mathrm{p}-\mathrm{Cl}-\mathrm{C}_{6} \mathrm{H}_{4}\right)$<smiles>[3H][V]</smiles><smiles>C=C[C@](C)(CO[OH+])[C@@]1(C(=O)OC)OC([Al])=CC1=O</smiles>

$(S, S)-6 a$
(Major)
Z
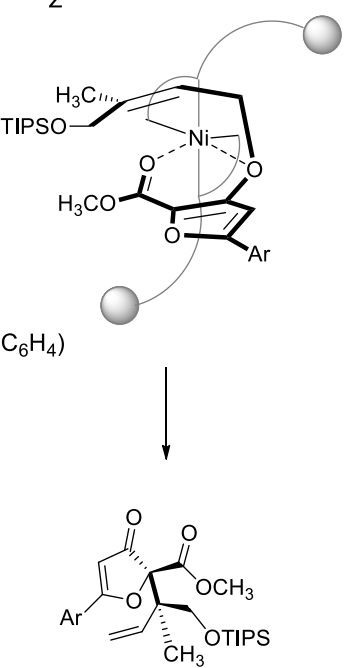

(S,R)-6a' (Major)

Figure 1. Proposed stereochemical model of Ni(II)-catalyzed asymmetric Claisen rearrangement of allyl furyl ether $\mathbf{5 a}$.

Recently, the Ireland-Claisen rearrangement involving $\mathrm{Cu}$-catalyzed reductive reactions was demonstrated by Chiu and co-workers. The Ireland-Claisen rearrangement is a useful pathway for forming carbon-carbon bonds from readily accessible ester carbonoxygen bonds [19,20]. In 2016, the copper hydride-catalyzed reductive Ireland-Claisen rearrangement was reported (Scheme 2) [21]. The rhodium hydride-catalyzed reaction was previously reported in 2002 [22], but the need for an expensive catalyst and moisturesensitive reductant limited the practicality of the protocol. Copper hydrides are economical and versatile metal catalysts for the conjugate reduction of Michael acceptors. Here, copper hydride and $(\mathrm{EtO})_{2} \mathrm{MeSiH}$ (as a reductant) afforded the silyl ketene acetals 9 from the acrylate 7 , followed by the Ireland-Claisen rearrangement. In the case of the silyl ketene acetals 9, the $(E)$-ketene acetal is more stable than the $(Z)$-isomer, which affects the diastereoselectivity of the reaction. 


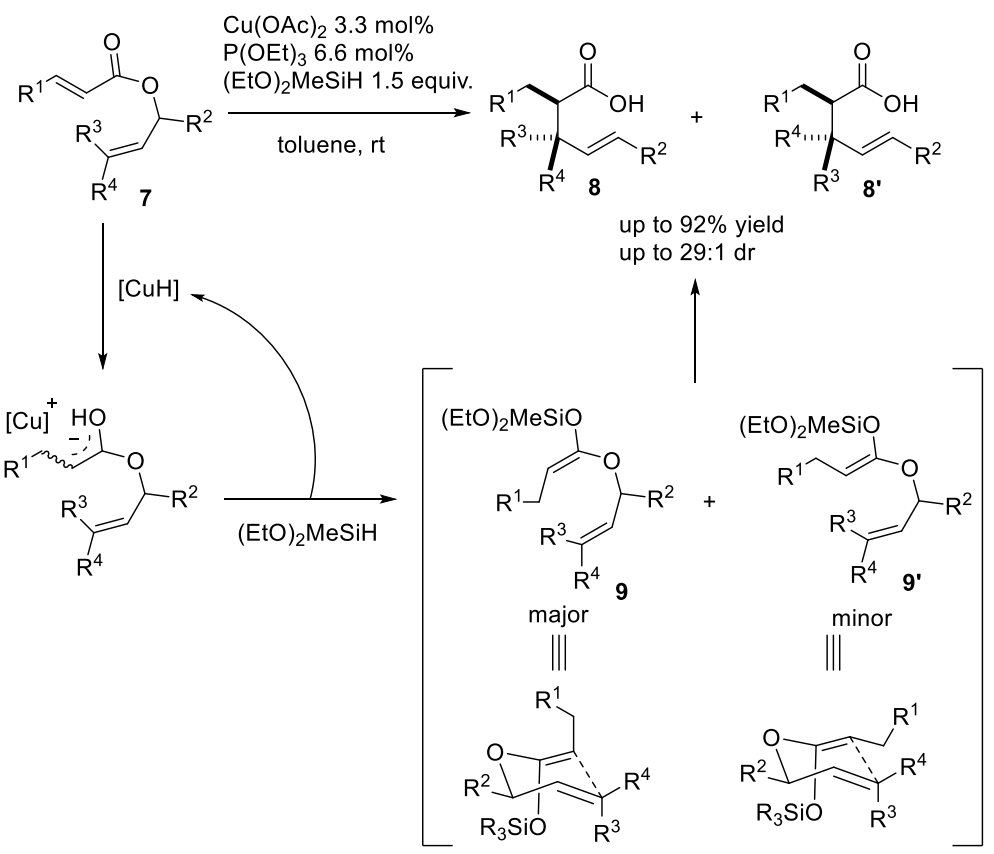

Scheme 2. Copper hydride-catalyzed reductive Ireland-Claisen rearrangement of hex-2-enyl acrylates.

In 2021, copper-catalyzed reductive Ireland-Claisen rearrangements were expanded to propargylic acrylates $\mathbf{1 0}$ and allylic allenoates $\mathbf{1 3}$ (Scheme 3) [23]. Silane and borane were used as reductants, and the substrates 10 and 13 were, respectively converted into the silyl and boron enolates $\mathbf{1 1}$ and $\mathbf{1 4}$ via the in situ conjugated reduction by a copper hydride catalyst. The generated enolates underwent the Ireland-Claisen rearrangement through a chair-like transition state. In the same way as the previous case, $(E)$-ketene acetals were the major product due to their stability, leading to the diastereoselectivity of the reaction.<smiles>[R]C#CC([R])([R])OC(=O)C=C</smiles>

10

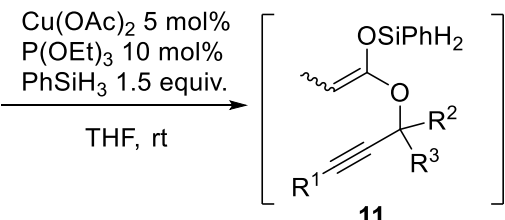

11<smiles>[R]C([R])=C([R])C(C)C(=O)O</smiles>

up to $98 \%$ yield up to $22: 1 \mathrm{dr}$

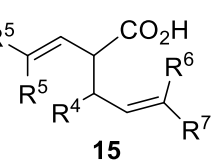

up to $99 \%$ yield up to $17: 1 \mathrm{dr}$

Scheme 3. Copper-catalyzed reductive Ireland-Claisen rearrangements of propargylic acrylates and allylic allenoates.

In 2020, the production of acetylenic and allenic amides via radical-mediated catalytic Claisen rearrangement was reported (Scheme 4) [24]. Copper or silver metal catalysts provided the radical-metal complex 21 with the corresponding isobutyronitrile radical 20 from AIBNs 17. The ketenimine complex 22 is generated by the capture of another isobutyronitrile radical 20 (Figure 2). Electrophilic ketenimine 22 was converted into propargyl vinyl ether 23 by the nucleophilic addition of propargyl alcohol 16, and the Claisen rearrangement ensued to form an allenic amide 19. Isomerization of allene 19 into the propargyl group 18 proceeded via 1,3-hydrogen transfer, which may be promoted by the stabilization of the attached aromatic group. The metal catalyst plays an important role 
in this reaction for promoting the Claisen rearrangement by the coordination effect, as well as through ketenimine generation by radical-radical cross-coupling.

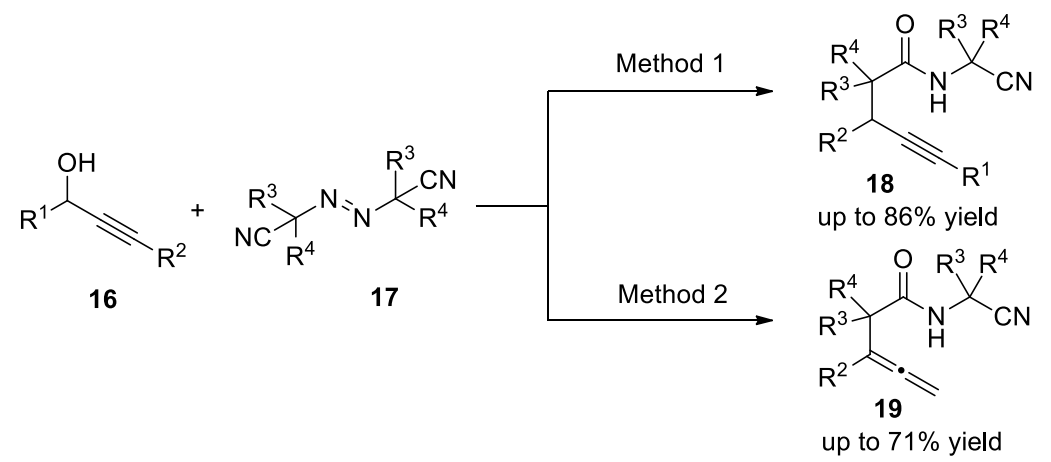

Method 1: $\mathrm{R}^{1} \neq \mathrm{H}, \mathrm{Cu}\left(\mathrm{CH}_{3} \mathrm{CN}\right)_{4} \mathrm{BF}_{4} 5 \mathrm{~mol} \%, 4-\mathrm{NO}_{2} \mathrm{C}_{6} \mathrm{H}_{4} \mathrm{~B}(\mathrm{OH})_{2} 10 \mathrm{~mol} \%$, DME, $100{ }^{\circ} \mathrm{C}$ Method 2: $\mathrm{R}^{1}=\mathrm{H}$, AgOTf $10 \mathrm{~mol} \%, \mathrm{DCM}, 100{ }^{\circ} \mathrm{C}$

Scheme 4. Radical-mediated catalytic Claisen rearrangement of propargylic alcohols with nitrilecontaining azoalkanes.<smiles>[R]C(C#[18CH])C(C)(C)C(=O)NC(C)(C)C</smiles><smiles>[R]/C=C(/F)C(C)(C)C(=O)NC(C)(C)C</smiles><smiles>CC(C)N=CCNC(C)(C)N=NC(C)(C)C</smiles>

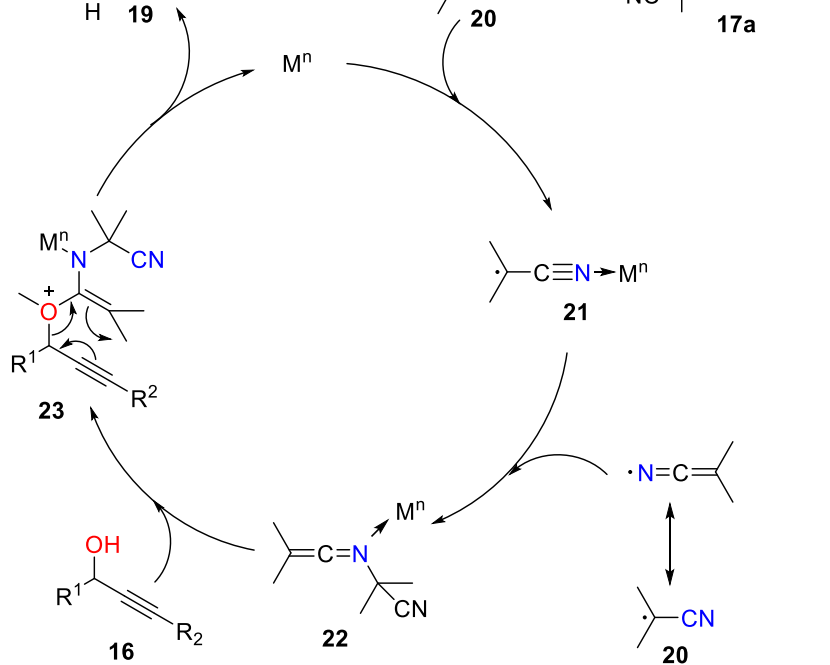

Figure 2. Proposed mechanism of radical-mediated catalytic Claisen rearrangement of propargylic alcohols with nitrile-containing azoalkanes.

Lanthanide(III) species are highly oxophilic Lewis acids, and several Claisen rearrangement reactions were achieved with the assistance of lanthanide catalysts. Ye and co-workers developed yttrium-catalyzed cascade reactions involving the hydroalkoxylation and Claisen rearrangement of ynamide substrates. Medium-sized lactams were synthesized by the yttrium(III)-catalyzed intramolecular cascade reaction (Scheme 5) [25]. Many tandem reactions involving intramolecular alkoxylation and Claisen reaction were developed with novel metal catalysts, such as gold and platinum [13]. Ye and co-workers reported the production of benzazocinones $\mathbf{2 5}$ and medium-sized lactams from ynamides $\mathbf{2 4}$ through yttrium(III)-catalyzed tandem intramolecular hydroalkoxylation and Claisen rearrangement. The reaction was initiated by the activation of ynamide $\mathbf{2 4}$ via the coordination of yttrium metal at the alkyne, followed by the intramolecular attack of the hydroxyl group on the activated alkyne to produce intermediate 26 . The ensuing proton transfer and Claisen rearrangement formed the lactam compound 25 . By using this reaction, both medium-sized 
lactams (8- to 12-membered cycles) and large-sized lactams (15- and 19-membered cycles) 28 were obtained through this highly efficient and atom-economical pathway.<smiles>[R]C#CN([Po])c1cc[R3]([R])cc1C(O)C([R])=C</smiles>

$P G$ 24

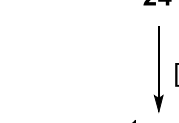

Y]

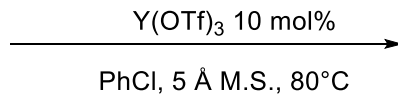

$P G=T s, B s, M B S, S_{2} P h$<smiles>[R]C=C([R1])C(O)c1ccccc1N([Pb])C[R]#CC[R]</smiles>

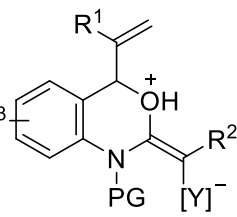

26<smiles>[R][R]1ccc2c(c1)C=C([R])CC([R])C(=O)N2[R5]</smiles>
up to $99 \%$ yield

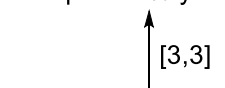
$[3,3]$

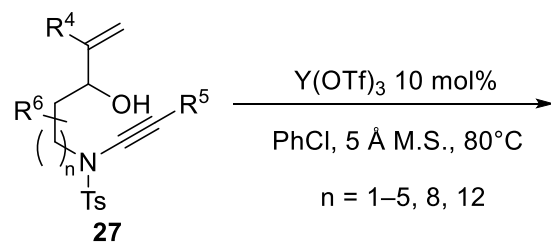

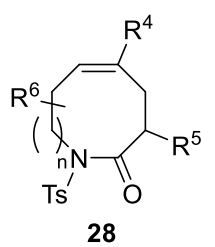

up to $99 \%$ yield

Scheme 5. Yttrium-catalyzed tandem intramolecular hydroalkoxylation and Claisen rearrangement of ynamides.

An intermolecular version of the reaction was also developed (Scheme 6) [26]. Alcohol 30 was added to a yttrium(III)-activated ynamide to form the vinyl yttrium intermediate 32, which by a sequential proton transfer and Claisen rearrangement furnished $\gamma, \delta$-unsaturated amide 31 in good yield with high diastereoselectivity.
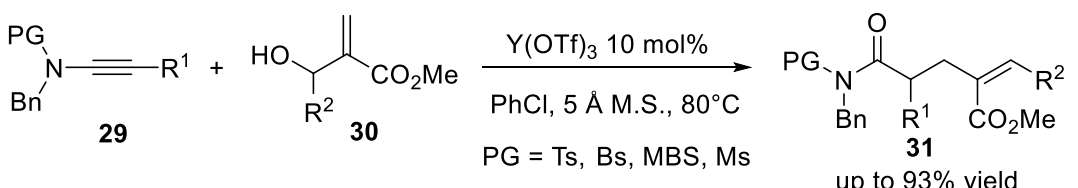
up to $93 \%$ yield

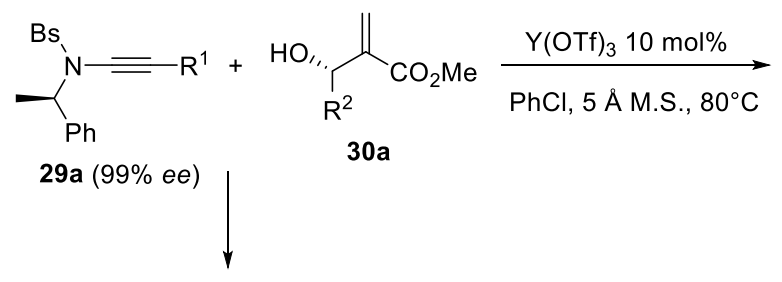

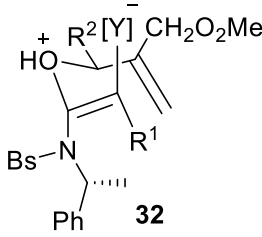

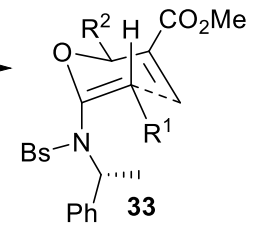

Scheme 6. Yttrium-catalyzed tandem intermolecular hydroalkoxylation and Claisen rearrangement.

A europium(III) species was also employed in the catalytic Claisen rearrangement system, and an example of the aryl-Claisen rearrangement of 2-bromoallyl aryl ethers 34 to produce useful ortho-2-bromoallylphenols 35 is reported (Scheme 7) [27]. The products bearing alkenylbromide functionality were expected to be valuable building blocks for the Suzuki-Miyaura cross-coupling reaction. 


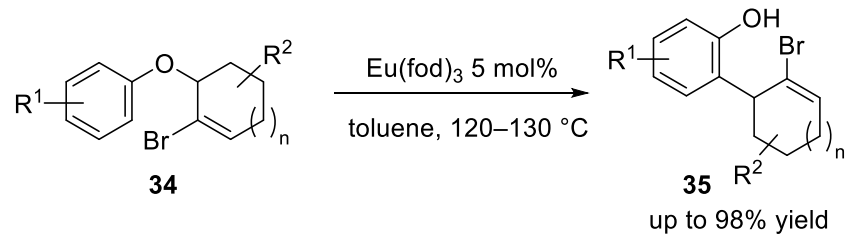

Scheme 7. Europium(III)-catalyzed aryl-Claisen rearrangement of 2-bromoallyl aryl ethers.

A scandium-catalyzed asymmetric Claisen rearrangement was developed in 2017 (Scheme 8) [28]. 2-Allyloxyindoles 36 and 2-propargyloxyindoles 38, respectively, provided 3-allyloxindoles 37 and 3-allenyloxindoles 39 with a high yield and enantioselectivity in the presence of a Sc(OTf $)_{3}$ catalyst and chiral bisoxazoline ligand L2. The gram-scale reaction was successfully demonstrated with $5 \mathrm{~mol} \%$ catalyst, affording $98 \%$ yield and $99 \%$ ee.<smiles>[R2]OC(=O)c1c(OCC([R])=C)[nH]c2cccc([X])c12</smiles>

36<smiles>[R]C1C(=O)Nc2ccccc2C1([R20])C</smiles>

37 up to $97 \%$ yield up to $95 \%$ ee

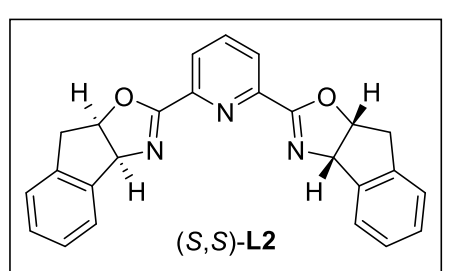

$(S, S)-$ L2

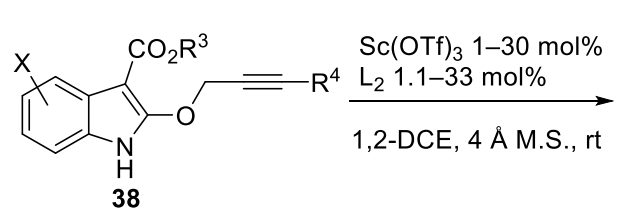

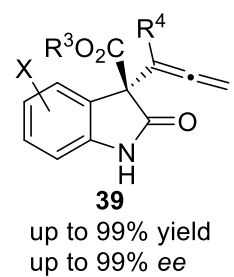

Scheme 8. Scandium(III)-catalyzed asymmetric Claisen rearrangement of 2-allyloxy- and 2propargyloxyindoles.

An iron(III)-catalyzed tandem reaction was developed for synthesizing naphtho[2,1b]furans 41 from $\beta$-naphthyl-substituted allenylmethyl ethers 40 via a tandem allenic Claisen rearrangement and dehydrogenative cyclization (Scheme 9) [29]. This highly regioand chemoselective reaction is initiated by the coordination of the iron catalyst to the oxygen of allene $\mathbf{4 0}$ (Figure 3). Thereafter, the Claisen rearrangement occurs through a chair-like transition state, and subsequent keto-enol tautomerization and homolytic cleavage produce the 2-naphthoxy radical $\mathbf{4 2}$ and $\mathrm{FeCl}_{2}$. Intramolecular radical cyclization produces the cyclic radical 43 , and the series of reactions involving oxidation by $\mathrm{FeCl}_{3}$ and deprotonation finally produce the naphtho[2,1-b]furan 41 . The reduced catalyst $\left(\mathrm{FeCl}_{2}\right)$ can be regenerated into $\mathrm{FeCl}_{3}$ by aerobic oxidation.

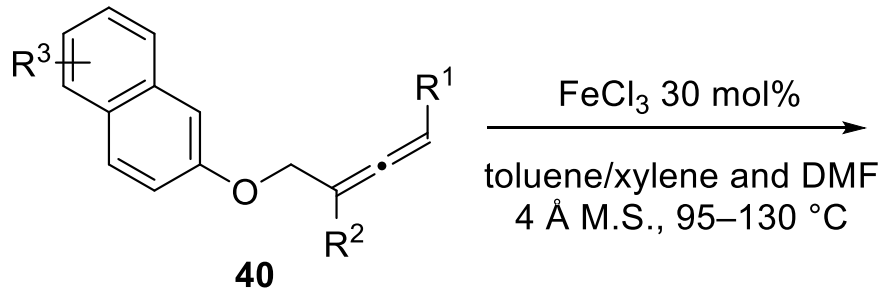<smiles>[R]C(=C)c1c([R])oc2ccc3c[R1]([H])ccc3c12</smiles>

Scheme 9. Iron(III)-catalyzed tandem allenic Claisen rearrangement and dehydrogenative cyclization. 


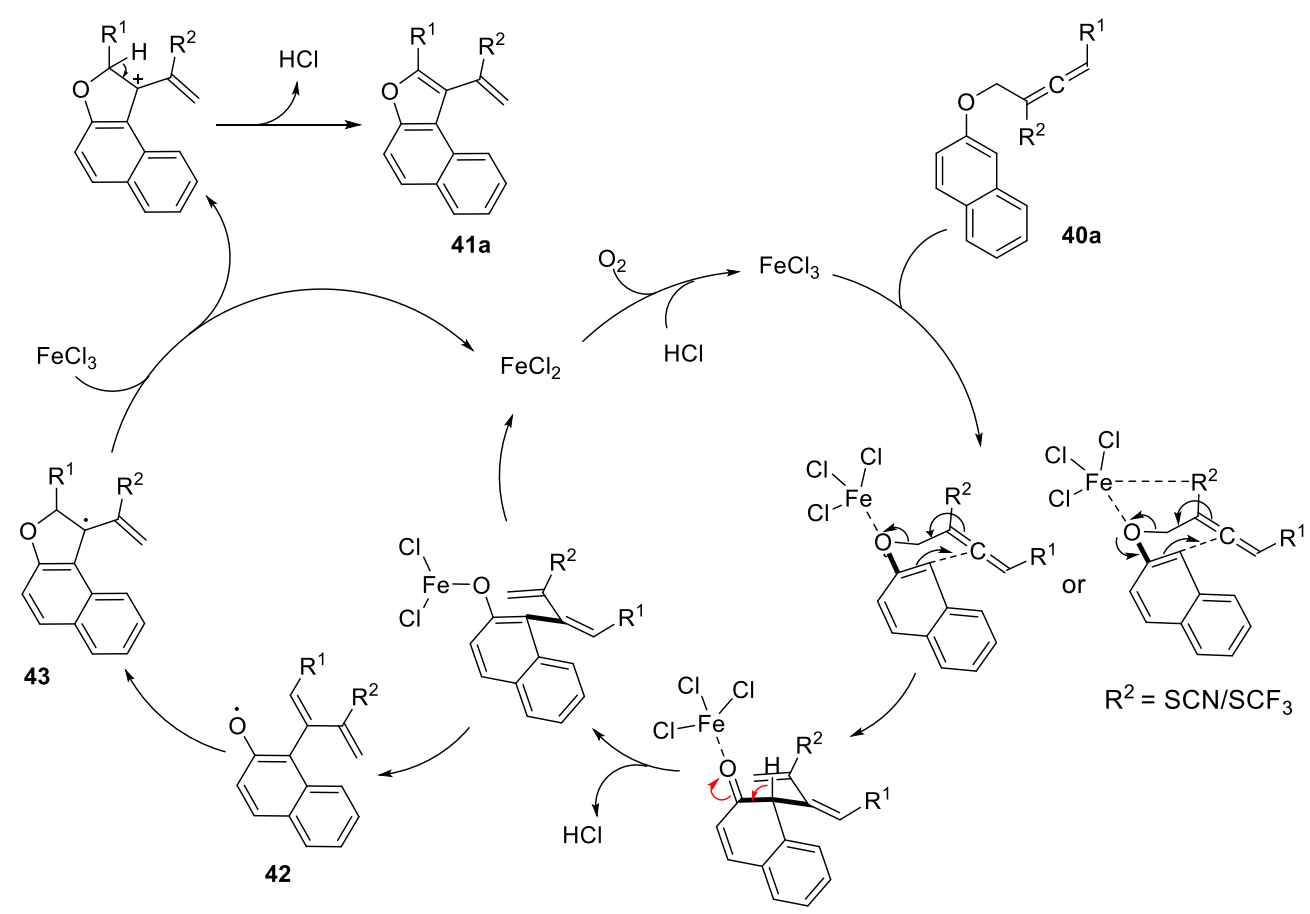

Figure 3. Plausible mechanism of iron(III)-catalyzed tandem allenic Claisen rearrangement and dehydrogenative cyclization.

Gold and platinum catalysts are excellent alkynophilic Lewis acids that can activate alkynes for reaction with nucleophiles; thus, a number of useful reactions involving tandem alkyne alkoxylation and Claisen rearrangement in the presence of novel metal catalysts were developed [13]. In 2019, $\alpha$-allylbutenolides 45 were obtained from allyl ynoates 44 by tandem gold(I)-catalyzed alkyne isomerization and cyclization, with subsequent Claisen rearrangement (Scheme 10) [30]. Ynoate substrate 44 was isomerized into allenoate 46 by a gold catalyst, and the cyclic cationic intermediate 47 was obtained by intramolecular cyclization. Due to the tertiary amine-functionality of ligand L3, aromatization was followed by deprotonation, and protodeauration delivered alkoxyfuran 48 . Subsequent Claisen rearrangement and double-bond migration produced the $\alpha$-allylbutenolide 45 in excellent yield.
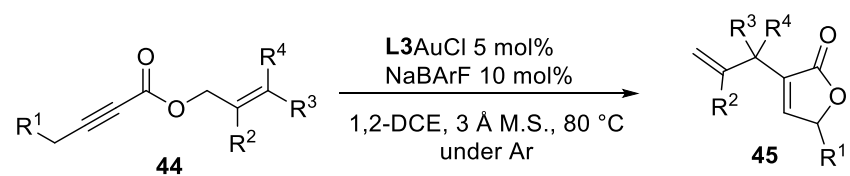

up to $95 \%$ yield
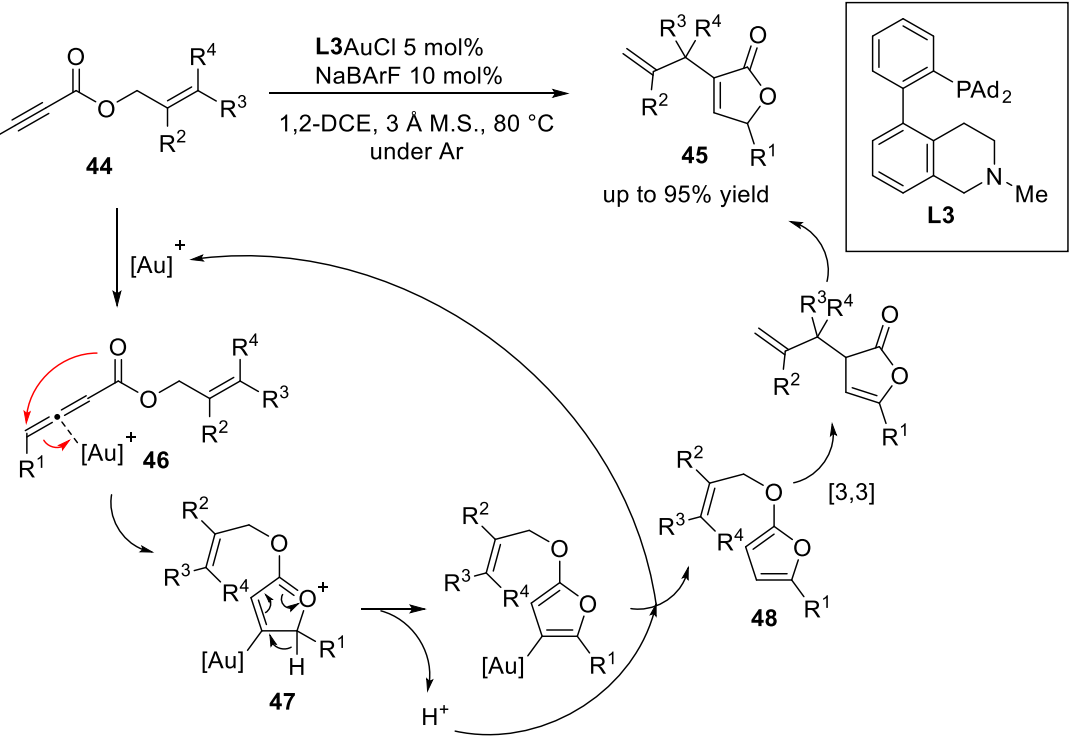

Scheme 10. Gold(I)-catalyzed tandem alkyne isomerization, cyclization, and Claisen rearrangement. 
Bimetallic cooperative catalytic reactions may enable the creation of new reactions by combining the advantages of each constituent catalytic system. For example, an achiral gold(I) catalyst and chiral nickel(II) catalyst operate sequentially to produce $\alpha$-allyl $\beta$ keto esters 51 with excellent yields and enantioselectivities via tandem intermolecular hydroalkoxylation and asymmetric Claisen rearrangement (Scheme 11) [31]. Initially, the gold-activated alkyne intermolecularly reacted with allylic alcohol $\mathbf{5 0}$ to produce the vinyl gold complex 52, and the subsequent protodeauration produced the vinyl allylic ether 53. The chiral nickel catalyst promoted asymmetric Claisen rearrangement to produce the product 51.

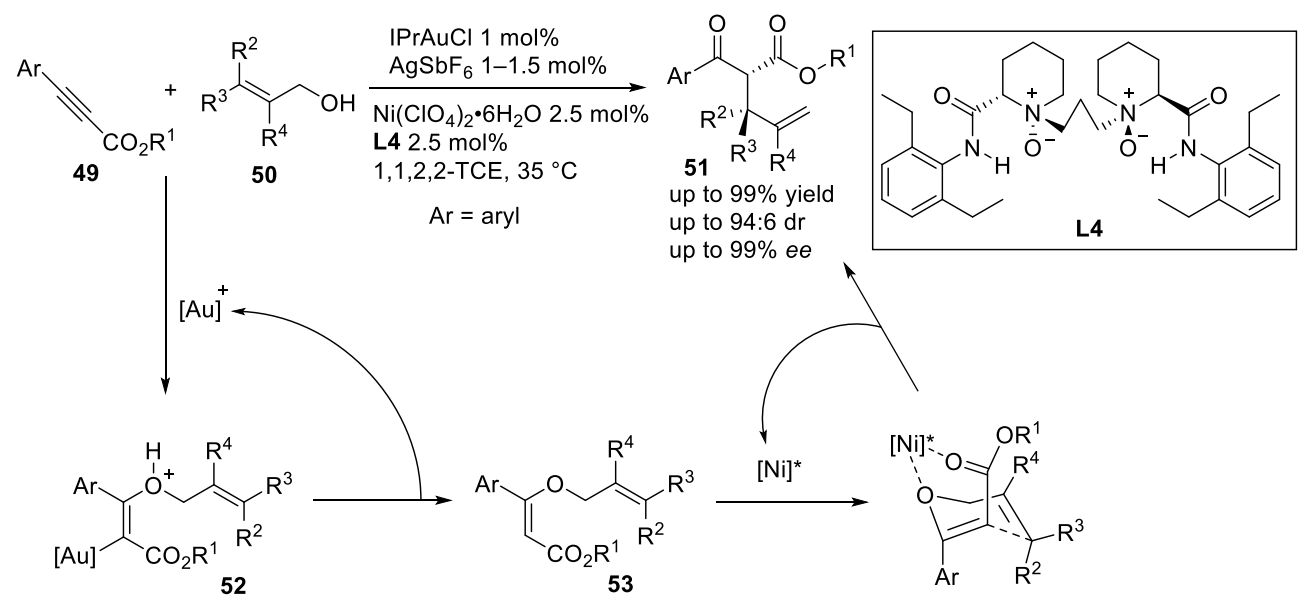

Scheme 11. Au/Ni bimetal-catalyzed tandem intermolecular hydroalkoxylation and asymmetric Claisen rearrangement.

Similarly, tandem insertion and asymmetric Claisen rearrangement catalyzed by a rhodium(II) and indium(III) bimetallic catalyst was developed (Scheme 12) [32]. NSulfonyl-1,2,3-triazole 54 firstly provided the rhodium(II) imino carbene intermediate 57, and the $O$-insertion of allyl alcohol 55 into the carbene intermediate 57 produced zwitterionic intermediate 58. Allyl vinyl ether 59 was obtained by proton transfer and $\mathrm{Rh}(\mathrm{II})$ regeneration, and chiral indium-mediated catalytic Claisen rearrangement delivered $\gamma$-oxo- $\beta$-amino ester 56 with high diastereo- and enantioselectivity.

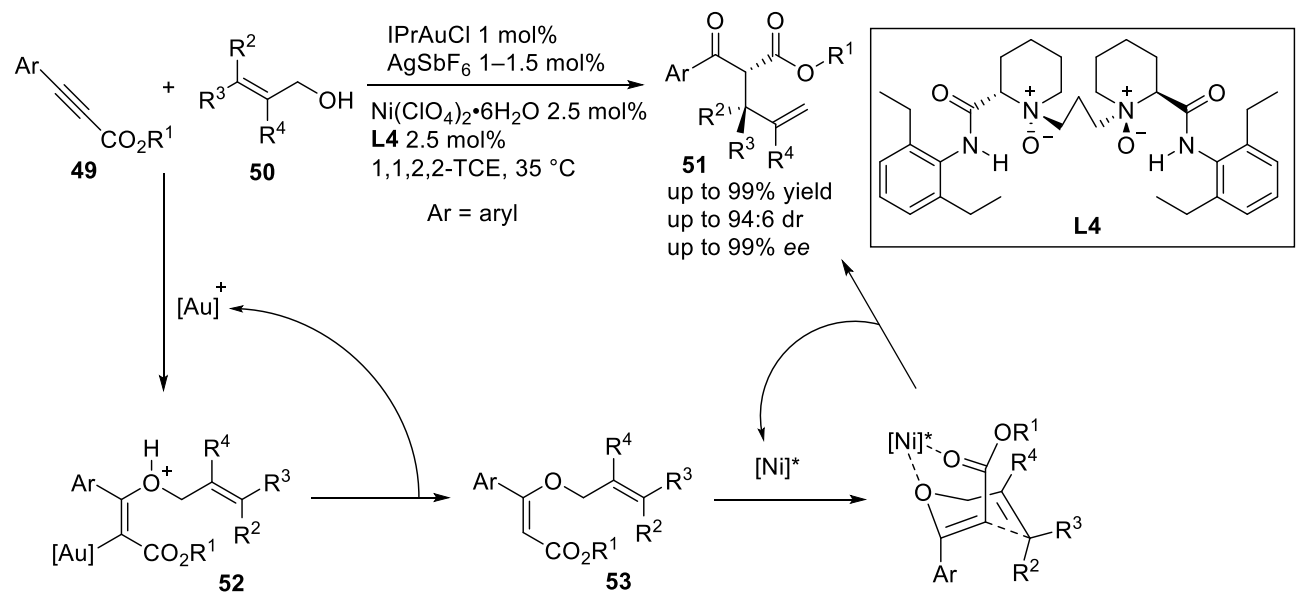

Scheme 12. Rh/In bimetal-catalyzed tandem insertion and asymmetric Claisen rearrangement.

\subsection{Organocatalyzed Claisen Rearrangement}

Organocatalyzed-Claisen rearrangement was also studied and various small molecules were successfully utilized as organocatalysts. Guanidinium salts, $N$-heterocyclic carbenes (NHCs), phosphoric acid and derivatives, and organic bases constitute representative 
examples. Inspired by the results of the Lewis acid-type transition metal catalysis in Claisen rearrangements [33], Claisen rearrangement with organocatalysis were also studied, and various small molecules were successfully utilized in the Claisen rearrangement or related transformations. Guanidinium salts, N-heterocyclic carbenes (NHCs), phosphoric acid and derivatives, and organic/inorganic bases are representative transition metal-free organocatalysts for the Claisen rearrangement.

An efficient and powerful organocatalyzed Claisen rearrangement was developed by Jacobsen and co-workers in 2008 (Scheme 13) [34]. Starting from urea and urea derivatives, which enabled H-bonding-based catalysis [35], the chemistry of the guanidinium salts was widely investigated for application to organic reactions. Due to the great accessibility and $N$-rich characteristics of guanidinium, various applications, including organocatalysis, were studied [36-38]. Notably, the simple $N, N^{\prime}$-diphenylguanidinium BArF salt $\mathbf{6 2}$ displayed great efficiency for Claisen rearrangement. The main reaction was performed at $22-40{ }^{\circ} \mathrm{C}$ with $20 \mathrm{~mol} \%$ of guanidinium salt. Moreover, this guanidium chemistry was successfully expanded to enantioselective reactions. As a compound having $C_{2}$-symmetry, the guanidiumium BArF salt 62 incorporating the trans-1-pyrrolo-2-aminocyclohexane moiety was efficiently subjected to asymmetric Claisen rearrangement. In general, $73-92 \%$ yields with $>81 \%$ ee were achieved and the diastereomeric ratios were determined to exceed 19:1. These pioneering studies enabled various organocatalyzed Claisen rearrangements, accompanied by the significant development of guanidine-based H-donor catalysts and ligands.

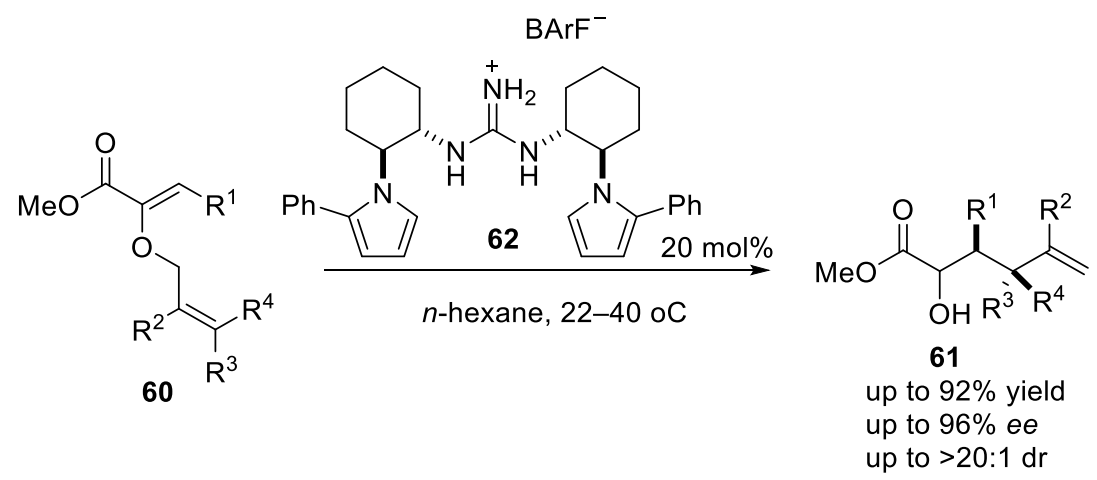

Scheme 13. Guanidinium-catalyzed asymmetric Claisen rearrangement.

In 2010, Bode and colleagues reported an enantioselective NHC-catalyzed Claisen rearrangement between ynals and enols to produce enantiomerically enriched dihydropyranones [39]. Most recently, in 2018, Vedachalam and co-workers reported a NHC-catalyzed Coates-Claisen rearrangement to construct the dihydropyran core of secoiridoids (Scheme 14a) [40]. Although traditional imidazolinium-based NHCs with both aliphatic chains and aromatic groups are not reactive in the Coates-Claisen rearrangement, the use of the fused NHC 66 afforded the corresponding compound dihydropyran-based lactone 65 in $62 \%$ yield and $82 \%$ ee. Interestingly, the absence of an external base (e.g., DBU or DIPEA) favored both the reactivity and stereoselectivity of the reaction. In general, the external base has dual roles: it activates the NHC salts and generates the reactive enol. However, in this system, the chloride anion from the NHC salts acts as an external mild base. Ultimately, the methodology was successfully applied to the preparation of monoterpene elenolide 67-based secoiridoids.

One year later, Rafinski's research team applied NHC catalysis to the aza-Claisen rearrangement to construct dihydropyrido[2,3-d]pyrimidine scaffolds (Scheme 14b) [41]. The reaction between $\alpha, \beta$-unsaturated aldehydes 68 and $N$-substituted 6-aminouracils 69 yielded the $N$-unprotected lactam moiety 70 through simultaneous $C-C$ bond formation and amide formation. In this case, all tested NHC salts were reactive for the aza-Claisen rearrangement. Indeed, the abnormal NHC with a single mesitylene substituent 71 was the most effective compound for aza-Claisen rearrangement. The reaction was generally performed in toluene solvent with $\mathrm{K}_{3} \mathrm{PO}_{4}$ as an external base. A broad substrate scope 
constituting both $\alpha, \beta$-unsaturated aldehydes 68 and $N$-substituted 6-aminouracils 69 was fully investigated. Moreover, the enantioselective aza-Claisen rearrangement was also achieved with chiral pinene-derived NHC salt 72. Although the addition of a Lewis acid or Brønsted acid did not accelerate the aza-Claisen rearrangement, a maximum yield of $84 \%$ and $67 \%$ ee were achieved with the chiral NHC salt. Lastly, the synthetic utility of the obtained products was clearly demonstrated.

(a) Asymmetric Coates-Claisen rearrangement of ynals and enols

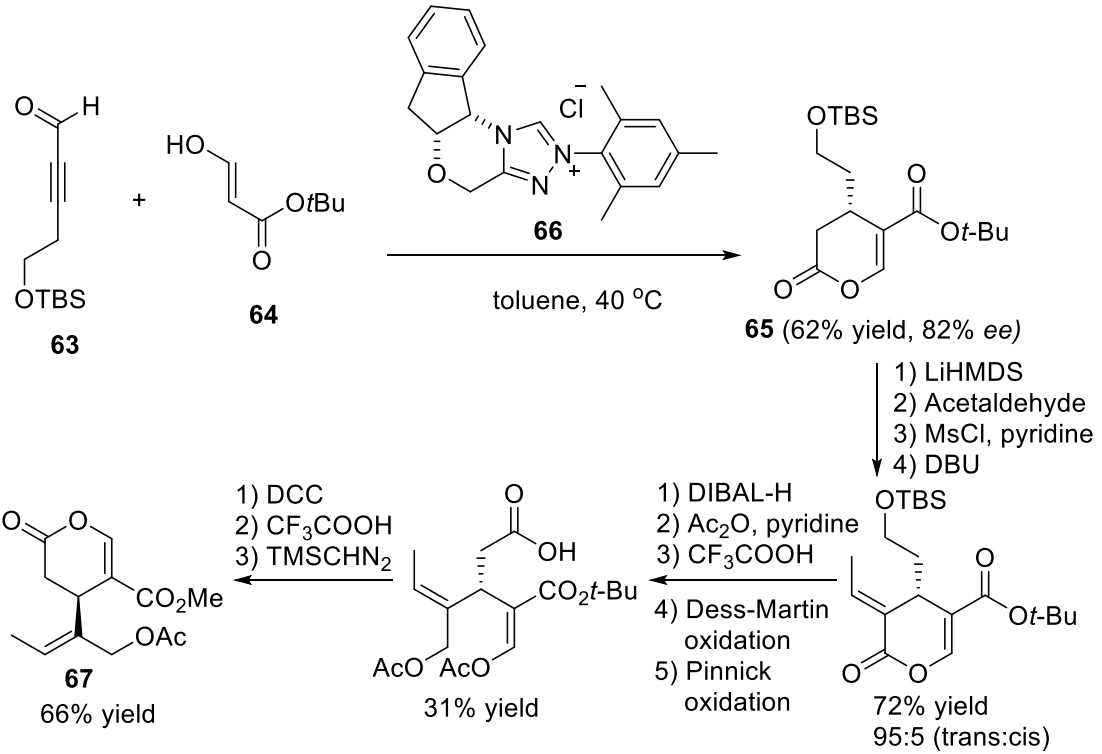

(b) Aza-Claisen rearrangement of $\alpha, \beta$-unsaturated enals with cyclic vinylogous amides

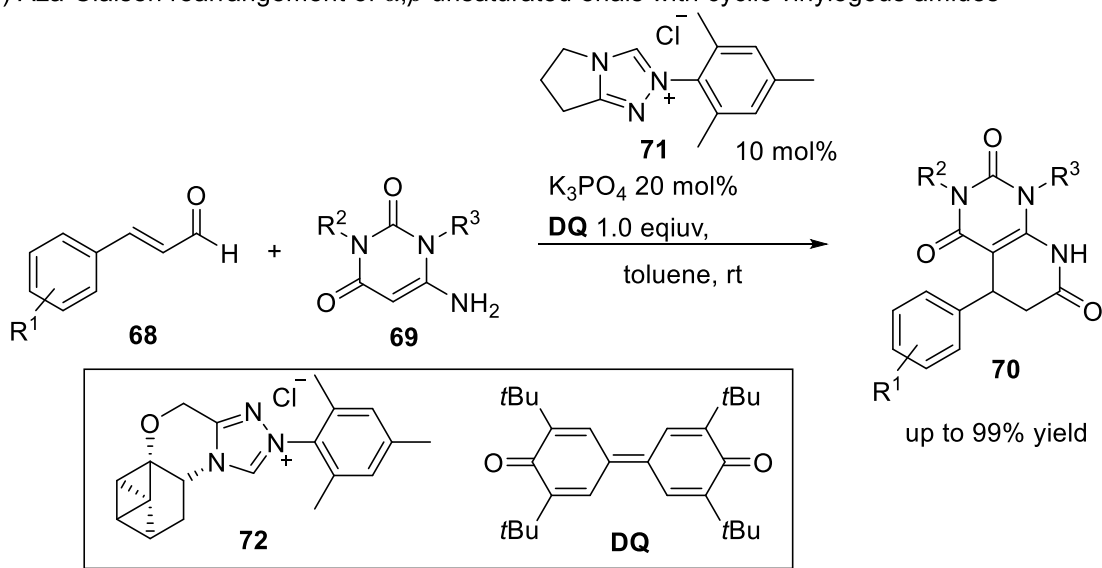

Scheme 14. NHC-catalyzed Claisen rearrangements.

Brønsted acids are also very important catalytic species for Claisen rearrangement. Ye's group applied a simple and strong Brønsted acid, bistriflimide $\left(\mathrm{HNTf}_{2},\left(\mathrm{CF}_{3} \mathrm{SO}_{2}\right)_{2} \mathrm{NH}, 1,1,1-\right.$ trifluoro- $N-(($ trifluoromethyl)sulfonyl)methanesulfonamide) in the synthesis of bridged [4.2.1] lactones 74 (Scheme 15a) [42]. This reaction consisted of multiple steps, where the carbo-oxygenation of alkenes and Claisen rearrangement are considered as the main steps in constructing the bridged lactone moiety. The proposed mechanism involves several cationic intermediates, including carbocations. Therefore, the low nucleophilicity of $\mathrm{Tf}_{2} \mathrm{~N}^{-}$ is important for maintaining the reactivity of multiple intermediates. 
(a) Metal-free synthesis of bridged [4.2.1] lactons via tandem intramolecular alkoxylation and Clasien rearrangement<smiles>[R]C(=C)C([R])OCc1c(C#CN(C)C)c2cc([R])ccc2n1[Pb]</smiles>

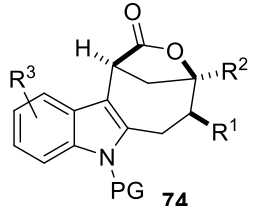

up to $86 \%$ yield

(b) Brønsted acid catalyzed spirolactam synthesis via intrameolecular hydroalkoxylation and Claisen rearrangement

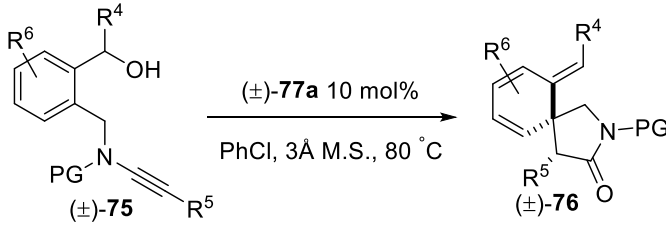

$( \pm)-75 R^{5}$

1) Chiral $77 \mathrm{~b} 1 \mathrm{~mol}$

Chiral 77b $1 \mathrm{~mol} \%$

PhCl/ethyl acetate $=3 / 1,-40^{\circ} \mathrm{C}$

2) DIPEA $25 \mathrm{~mol} \%$

$100^{\circ} \mathrm{C}$ up to $94 \%$ yield ( $>20: 1 d r$ )

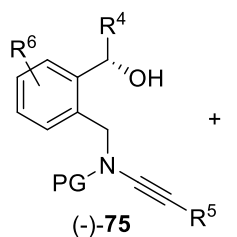

(-)-75

up to $49 \%$ yield up to $98 \%$ ee

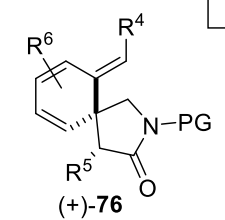

up to $49 \%$ yield up to $96 \%$ ee

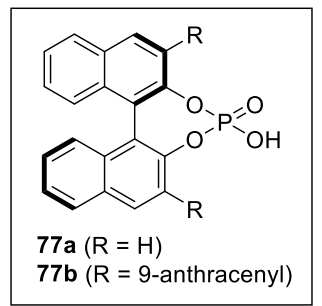

(c) Chiral phospate catalyzed enantioselectivie allenoate-Claisen rearrangement

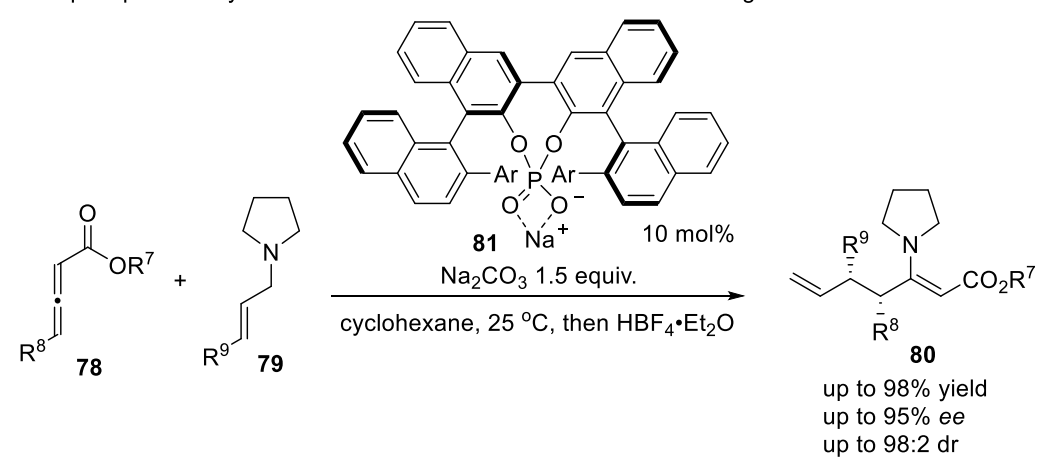

Scheme 15. Brønsted acid-catalyzed Claisen rearrangements.

Two years later, Ye's group expanded the Brønsted acid-catalyzed Claisen rearrangement to another useful Brønsted acid, phosphoric acid, in an enantioselective manner (Scheme 15b) [43]. This is a [3,3]-stereospecific reaction accompanied by the dearomatization of non-activated arenes. Starting from the benzyl alcohol-tethered ynamide 75, the main reaction was performed with strong Brønsted acids, such as $\mathrm{TfOH}, \mathrm{TsOH}$, or $\mathrm{MsOH}$. Moreover, the BINOL-derived phosphoric acid 77a was the most active agent for producing the dearomatization product 76. Moreover, the chiral nature of the BINOL-derived phosphoric acid $\mathbf{7 7 b}$ allowed the kinetic resolution of racemic ynamides $( \pm)-75$ to afford the recovered ynamides (-)-75 and spirolactames (+)-76. A variety of substrates with various substituents was tested, and the synthetic utility of the dearomatized spirolactam moiety was also clearly demonstrated.

In 2020, the research groups of Sigman and Toste utilized the double-axial chiral phosphoric acid sodium salt $\mathbf{8 1}$ to catalyze the reaction of allenolates $\mathbf{7 8}$ and tertiary allylaminers 79 to obtain $\beta$-amino acid derivatives 80 (Scheme 15c) [44]. The effect of the ligand structure on the allenolate-Claisen rearrangement, as well as the effect on the preparation of doubly axially chiral phosphonate, were investigated in depth. The DFT calculations fully supported the proposed mechanism and observed selectivity.

In 2019, Cramer and co-workers reported an organocatalyst for the efficient reductive Ireland-Claisen rearrangement of allyl acrylates 82 (Scheme 16) [45]. The traditional Ireland- 
Claisen rearrangement typically requires stoichiometric strong bases and low-temperature conditions. At the same time, the reductive Ireland-Claisen rearrangement employing transition metal catalysis and a silane additive $\left(\mathrm{R}_{3} \mathrm{SiH}\right)$ was developed. In that study, Cramer and co-workers utilized the unique 1,3,2-diazaphospholene 84 as a catalyst and reductant for HBpin to produce a strong hydride donor $\mathbf{8 5}$, and the initial addition of 85 can provide either intermediate $86 \mathrm{a}$ or $\mathbf{8 6 b}$. From $86 \mathrm{a}$ (Path a), $\sigma$-bond metathesis with HBpin produced enolate 87, and following [3,3]-sigmatropic rearrangement delivered a boron carboxylate 89 . Intermediate $\mathbf{8 6 b}$ has more options to reach the desired carboxylate 89 . One is $\sigma$-bond metathesis with HBpin, followed by [3,3]-sigmatropic rearrangement (Path b). The other pathway uses the direct [3,3]-sigmatropic rearrangement to produce phosphorus carboxylate 88, and the desired carboxylate 89 was produced by the regeneration of 85 (Path c). According to Path c, the diastereoselectivity and the enantioselectivity could be controlled by chiral diazaphospholene catalyst. The authors demonstrated a catalytic asymmetric reductive Claisen rearrangement from 82a with chiral 90, with an enantiomeric ratio of $68.5: 31.5$ in $96 \%$ yield $(11.7: 1 \mathrm{dr})$.

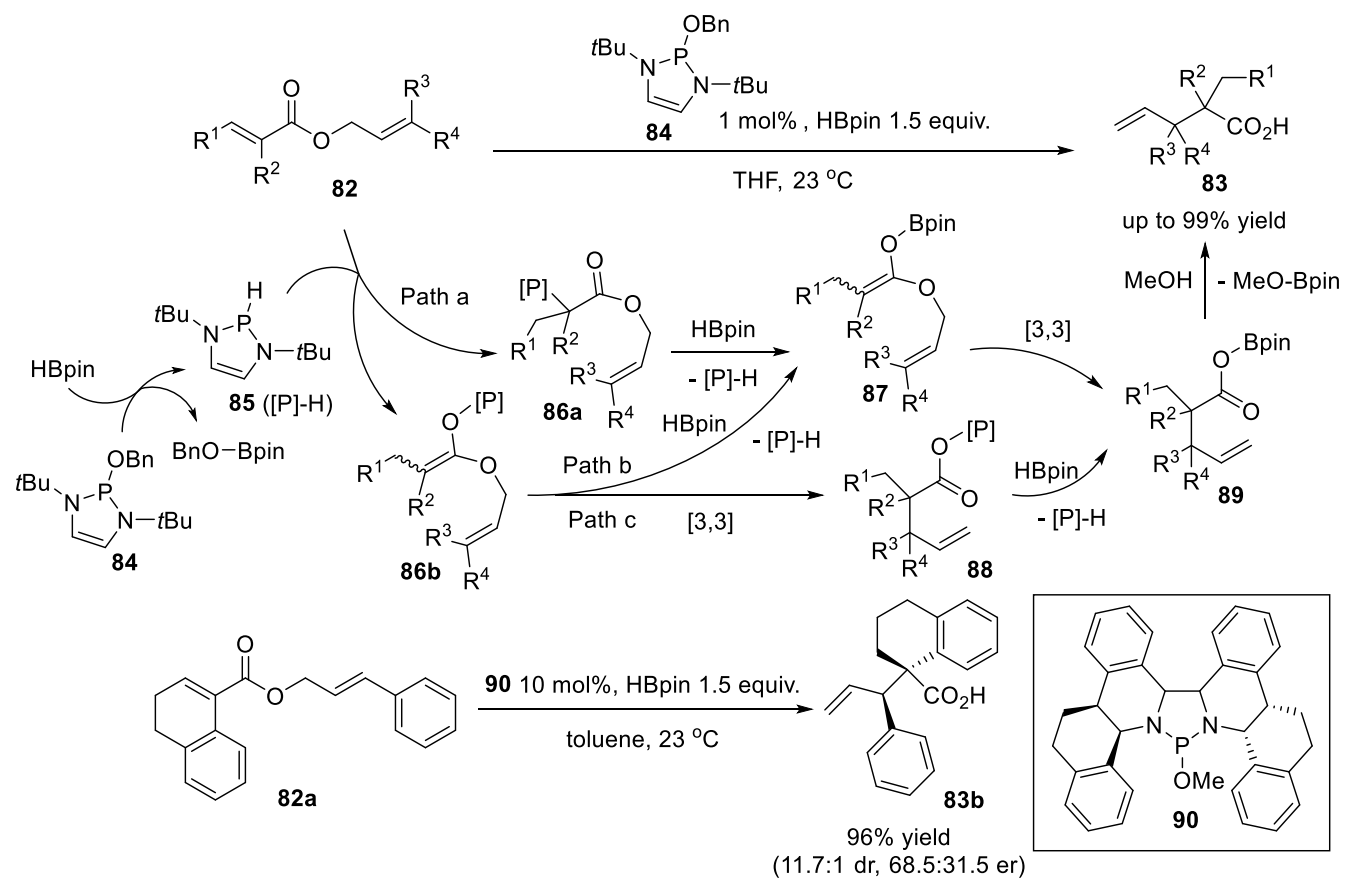

Scheme 16. 1,3,2-Diazaphopholene-catalyzed Ireland-Claisen rearrangement.

As an organocatalyst, simple Lewis bases are also employed in the tandem hydroalkoxylation-Claisen rearrangement-cyclization (Scheme 17) [46]. The representative organic base 1,4-diazabicyclo[2.2.2] octane (DABCO) was revealed to be an efficient Lewis base catalyst for the hydroalkoxylation of ynones 92 with allylic cyanohydrin 91 to produce $O$-alkenyl substituted cyanohydrin 94 and a subsequent Claisen rearrangement to 1,3-dicarbonyl compounds 95. Finally, 2,3-dihydrofurans 93 were obtained through tautomerism and an intramolecular oxa-Michael addition. Furthermore, the sequential addition of primary amines provided 2,3-dihydropyrroles 97 by aza-Michael addition. A broad range of 2,3-dihydrofurans 93 and 2,3-dihydropyrroles 97 was produced by this Lewis base-catalyzed tandem reaction in a good-to-high yield from the readily available materials. 
(a) Synthesis of 2,3-dihydrofurans

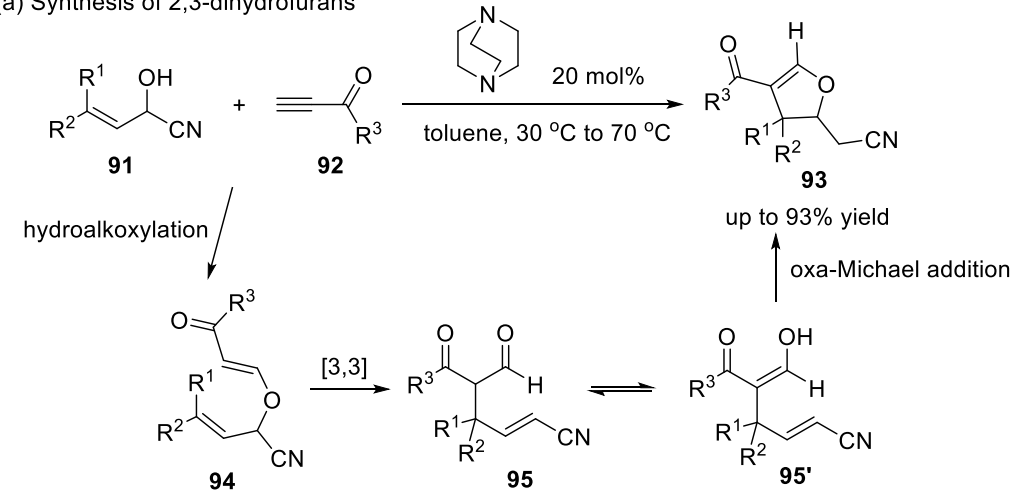

(b) Synthesis of 2,3-dihydropyrroles

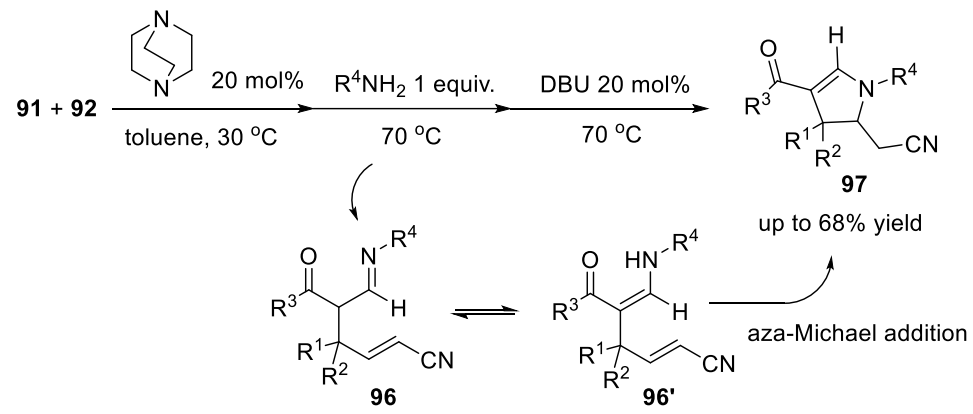

Scheme 17. DABCO-catalyzed Claisen rearrangement.

In 2021, the Glorius Group reported the synthesis of tertiary carboxylic acids by merging a Giese-type radical addition and an Ireland-Claisen rearrangement (Scheme 18) [47]. The photocatalytic-enabled reductive radical-polar crossover (RRPCO) and [3,3]-sigmatropic Ireland-Claisen rearrangement were successfully combined under transition metal-free photoredox conditions. The 4CzIPN molecule (1,2,3,5-tetrakis(carbazol-9-yl)-4,6-dicyanobenzene) was revealed to be the most efficient photocatalyst for this process. This methodology enabled the efficient synthesis of highly interesting $\alpha, \alpha$-dialkylated $\gamma$-amino butyric acids (i.e., GABA derivatives). Although the Ireland-Claisen rearrangement is not directly performed by $4 \mathrm{CzIPN}$, the coexistence of two different catalytic systems and their connection afforded insight and highlighted the challenges for further applications.

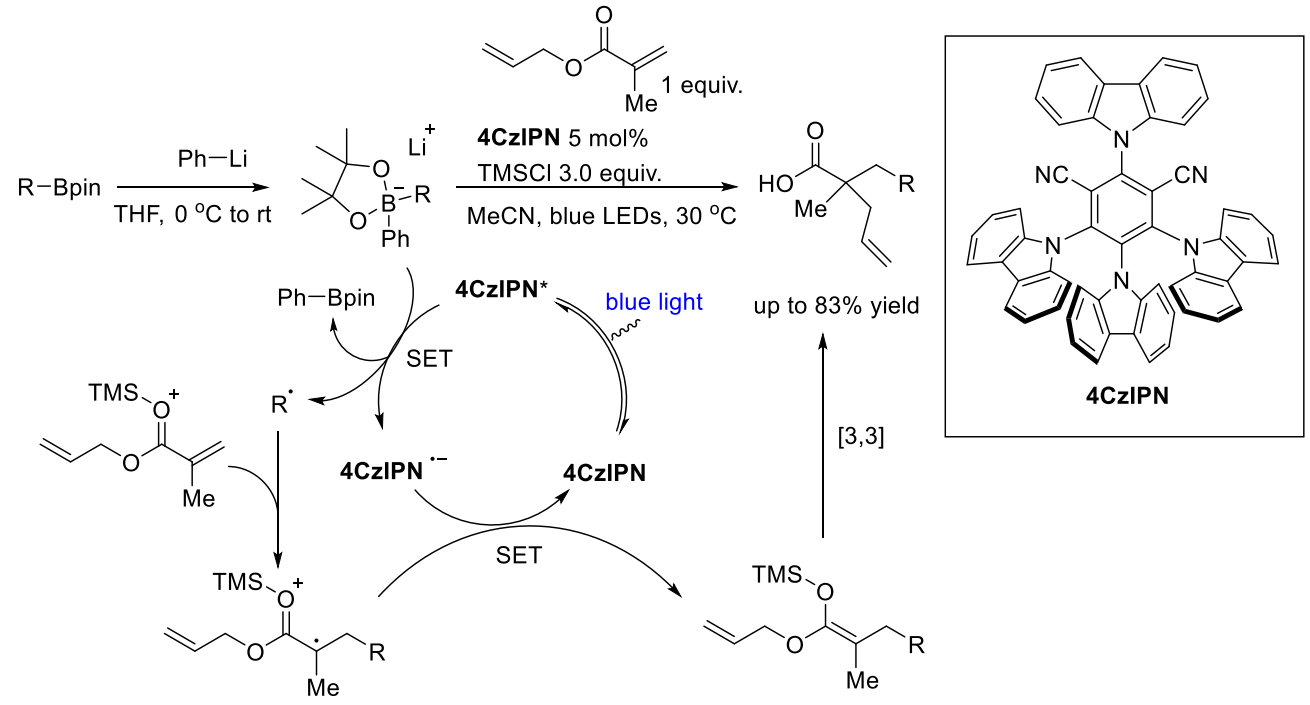

Scheme 18. Photoredox-mediated reductive radical-polar crossover (RRPCO) and Ireland-Claisen rearrangement. 


\subsection{Catalytic Aza- and Thio-Claisen Rearrangement}

Apart from oxygen-containing compounds, nitrogen- and sulfur-containing congeners are also well-established for the [3,3]-sigmatropic rearrangement, i.e., aza- and thio-Claisen rearrangement, to produce the corresponding aza- and thio-compounds. Similar to previously described Claisen rearrangements involving oxygen-containing compounds, these reactions incorporate various catalysts.

In 2016, Sakai and co-workers reported the copper-catalyzed [3 +2 ] annulation of 2,3-disubstituted indoles 100 from propargylic acetates 99 and anilines 98 via aza-Claisen rearrangement (Scheme 19) [48]. The reaction starts from the generation of propargylic amine 101 by $\mathrm{C}-\mathrm{N}$ bond formation involving aniline 98 and propargylic acetate 99 . AzaClaisen rearrangement occurs through the $\mathrm{Cu}$-activated alkyne 101, and intramolecular cyclization and protodemetalation ensue the formation of the desired 2,3-disubstituted indoles 100.

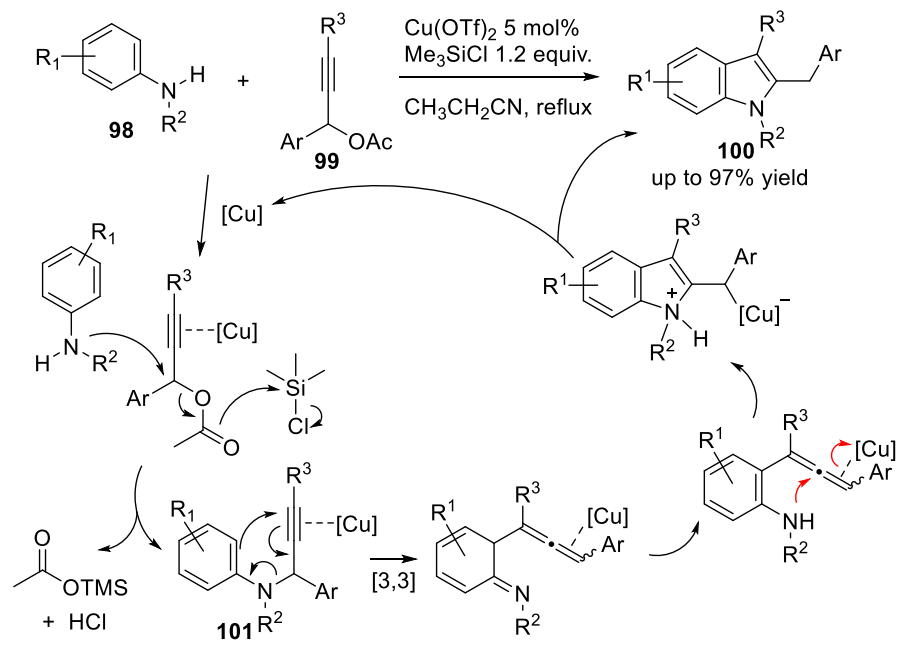

Scheme 19. Copper-catalyzed [3 + 2] annulation via aza-Claisen rearrangement.

Cao's group developed the copper(I)-catalyzed stereoselective synthesis of $\alpha$-allylic amidines 104 via cascade ketenimine formation and aza-Claisen rearrangement (Scheme 20) [49] The reaction was successfully demonstrated on the gram scale using only $1 \mathrm{~mol} \%$ catalyst in a one-pot synthesis with three components, namely, the terminal alkyne $\mathbf{1 0 2}$ and $\mathrm{TsN}_{3}$, and tertiary allylic amine 103. Ketenimine intermediate 105 was obtained by the Cu-catalyzed reaction [50,51], and top- or bottom-side additions of the tertiary amine delivered diamine intermediates 106. More stable chair-like transition state $\mathbf{1 0 6 b}$ provided the $\alpha$-allylic amidine 104 containing a quaternary carbon center, with excellent diastereoselectivity.

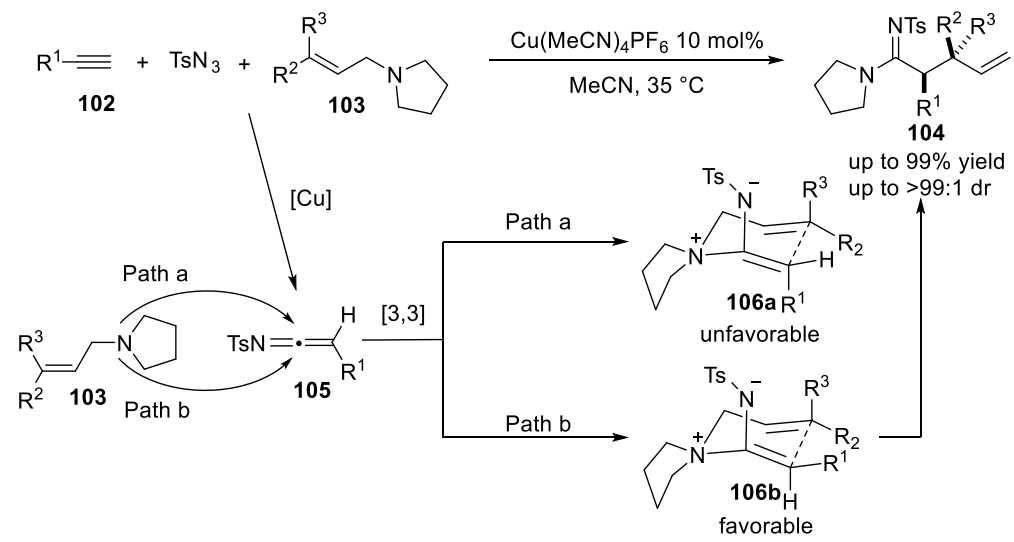

Scheme 20. $\mathrm{Cu}(\mathrm{I})$-catalyzed three-component reaction of $\alpha$-allylic amidines via cascade ketenimine formation and aza-Claisen rearrangement. 
Breinbauer's group reported the Pd-catalyzed $\alpha$-allylation of imine-containing heterocycles and subsequent aza-Claisen rearrangement (Scheme 21) [52]. This reaction is initiated by $N$-allylation followed by deprotonation to deliver the $N$-allylvinylamine 109, which transforms into imine $\mathbf{1 0 8}$ by the aza-Claisen rearrangement.

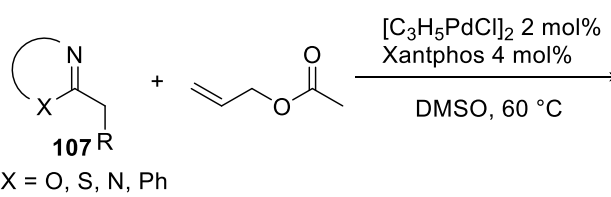

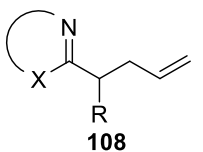
up to $96 \%$ yield

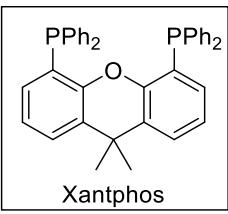

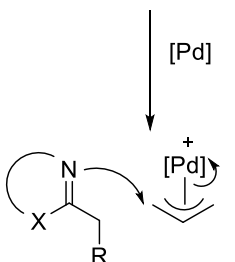

Pd]

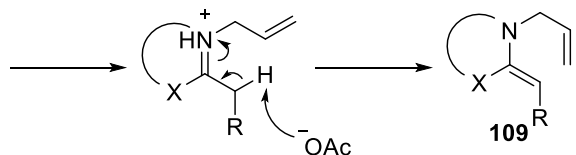

Scheme 21. Pd-catalyzed $\alpha$-allylation of imine-containing heterocycles via aza-Claisen rearrangement.

In the rearrangement of $N$-alloc- $N$-allyl ynamides 110, the Pd catalyst plays two distinct roles: decarboxylative $\pi$-allylic rearrangement [53] and Pd-promoted aza-Claisen rearrangement (Scheme 22) [54]. Based on the DFT calculation, the aza-Claisen rearrangement incorporates the $\operatorname{Pd}(0)$ catalyst to reduce the energy barrier, where the results are well-matched with deuterium-labeling and crossover experiments.

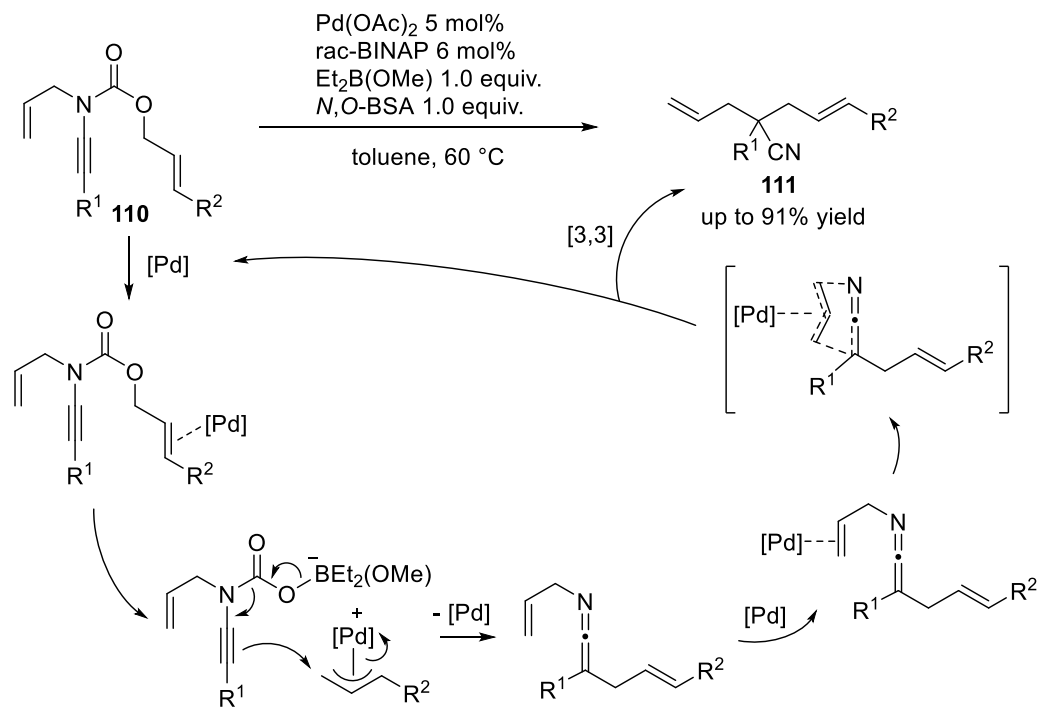

Scheme 22. Pd-catalyzed rearrangement of $N$-alloc- $N$-allyl ynamides via decarboxylative $\pi$-allylic rearrangement and aza-Claisen rearrangement.

In 2018, Stevens and co-workers developed an Au-catalyzed domino reaction involving cyclization and aza-Claisen rearrangement for forming highly substituted pyrazoles in a one-pot procedure (Scheme 23) [55]. The reaction of $N$-allyl hydrazine with alkynyl aldehyde or ketone $\mathbf{1 1 3}$ produced hydrazone 115. Due to the high thermal stability, hydrazine oxalate $\mathbf{1 1 2}$ was used instead of hydrazine. The generated hydrazone intermediate $\mathbf{1 1 5}$ underwent 5-endo-dig cyclization in the presence of the Au catalyst, and the subsequent [3,3]-sigmatropic rearrangement produced the desired polysubstituted pyrazoles 114. 


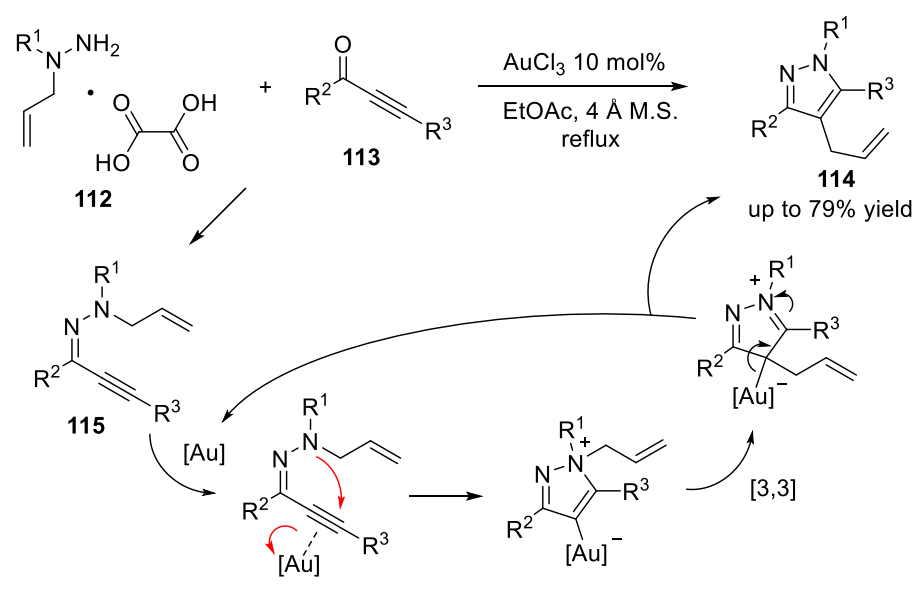

Scheme 23. Au-catalyzed domino reaction involving 5-endo-dig cyclization and aza-Claisen rearrangement for forming polysubstituted pyrazoles.

In 2020, the Feng's group developed the nickel(II)-catalyzed asymmetric thio-Claisen rearrangement of $\alpha$-diazo pyrazoleamides (Scheme 24) [56]. The chiral nickel carbene complex 119 is initially formed from diazo compound 117, and the enantioselective nucleophilic attack of thioindole 116 follows to produce sulfonium ylide $\mathbf{1 2 0}$. The subsequent thio-Claisen rearrangement delivers the highly optically pure C3-substituted thioindole 118.

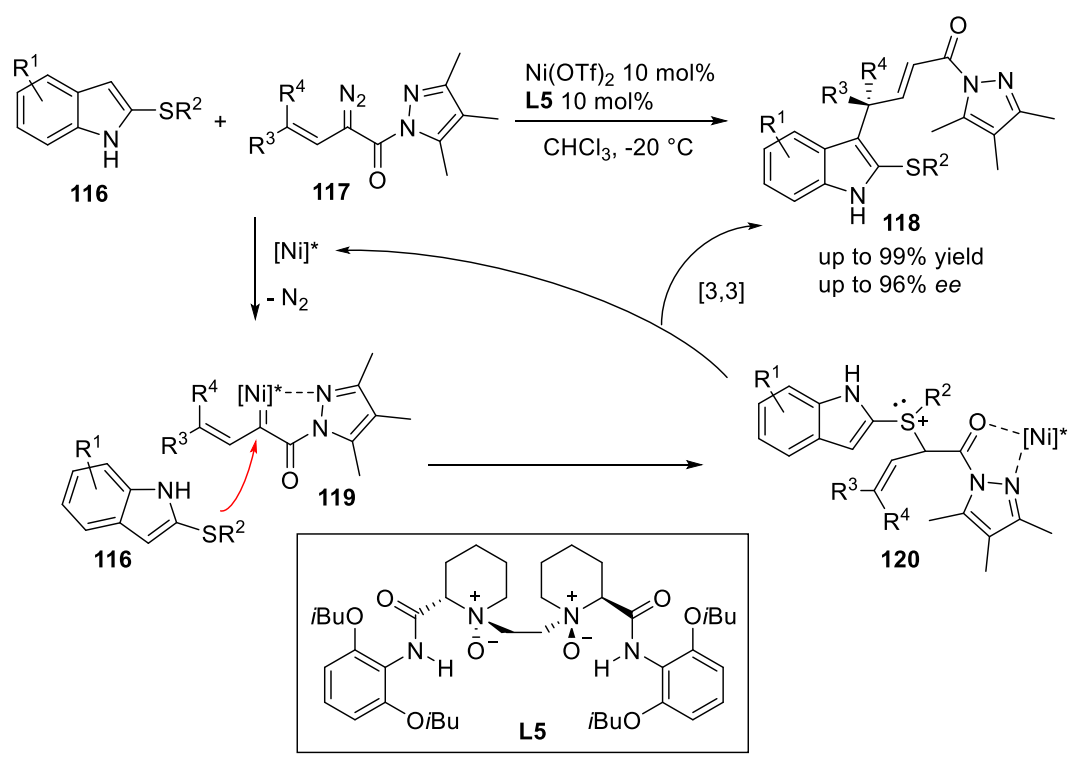

Scheme 24. Nickel(II)-catalyzed asymmetric thio-Claisen rearrangement of $\alpha$-diazo pyrazoleamides.

\section{Catalytic Cope Rearrangement}

\subsection{Transition Metal Catalyzed Cope Rearrangement}

Recently, various Ir-catalyzed tandem reactions involving asymmetric allylation and Cope rearrangement were developed with chiral phosphoramidite ligands. For example, in 2016, Stolz and colleagues reported an Ir-catalyzed asymmetric allylic alkylation and Cope rearrangement toward the $\gamma$-alkylation of $\alpha, \beta$-unsaturated malonates 123 (Scheme 25) [57]. The $\alpha, \beta$-unsaturated carbonyl compound $\mathbf{1 2 1}$ acts as a nucleophile to produce the 1,5-diene 124 by asymmetric allylic alkylation, and subsequent Cope rearrangement delivers the highly optically pure product 123. 


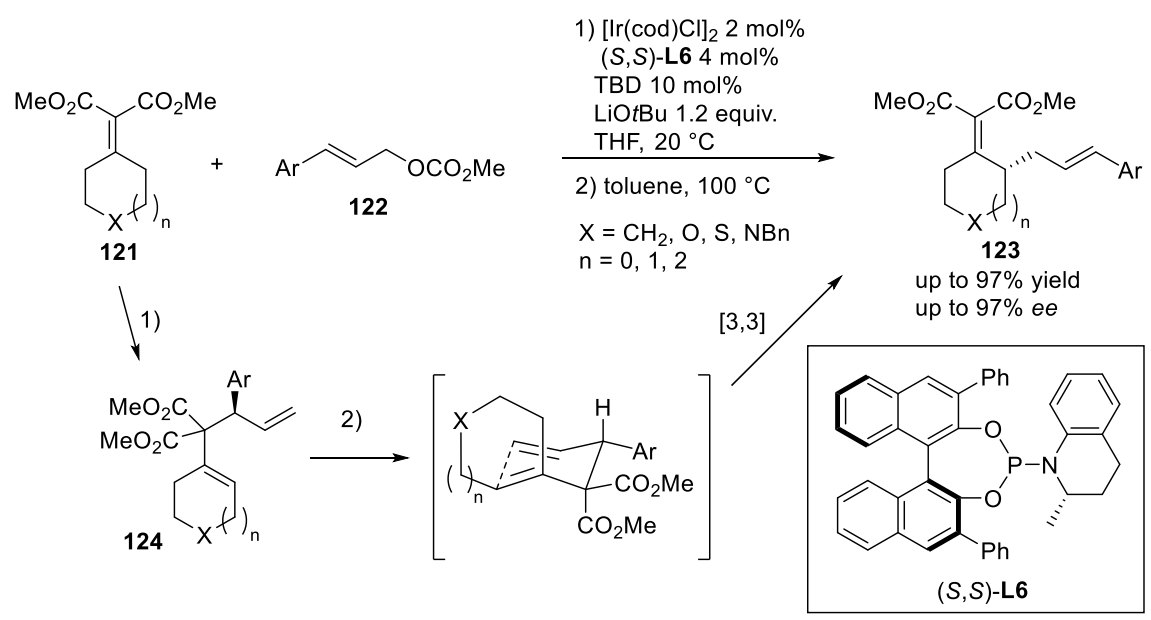

Scheme 25. Ir-catalyzed sequential one-pot reactions involving asymmetric allylic alkylation and Cope rearrangement.

In 2019, the Ir-catalyzed asymmetric synthesis of $\alpha$-tetrasubstituted $\alpha$-trifluoromethyl homoallylic amines was reported by Wang's group [58] and Niu's group [59] at the same time (Scheme 26). Both groups used fluoroenylidene trifluoromethylamines $\mathbf{1 2 5}$ and allylic carbonates 126 as starting materials; the reaction involved a catalytic asymmetric tandem umpolung allylation of the imine and aza-Cope rearrangement. When $\mathrm{R}^{1}$ was a phenyl group, a stabilizing $\pi-\pi$ interaction between the phenyl and fluorenyl rings in the allylated intermediate 128 was observed by X-ray crystallography.

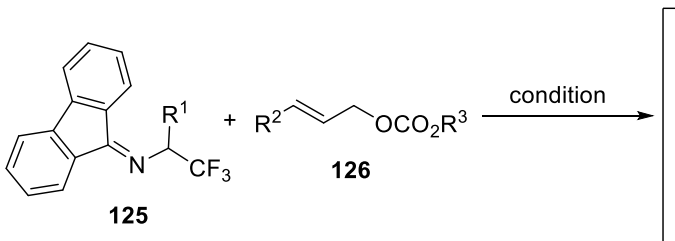

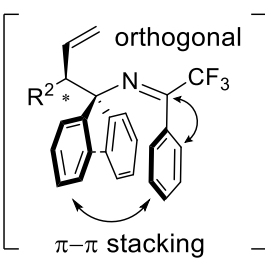

128

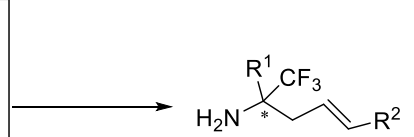

127 up to $95 \%$ yield up to $>99 \%$ ee

\footnotetext{
Wang's group: $\mathrm{R}^{1}=\mathrm{Ar}, \mathrm{H}, \mathrm{R}^{3}=\mathrm{Me},\left[\mathrm{Ir}(\operatorname{cod}) \mathrm{Cl}_{2} 2.5 \mathrm{~mol} \%,(S, S, S)-\mathrm{L} 75 \mathrm{~mol} \%\right.$, DBU 1.0 equiv. toluene, $25^{\circ} \mathrm{C}$ then work up with $\mathrm{NH}_{2} \mathrm{OH} \cdot \mathrm{AcOH}$

Niu's group: $\mathrm{R}^{1}=\mathrm{Ar}, \mathrm{R}^{3}=t \mathrm{Bu},[\mathrm{Ir}(\operatorname{cod}) \mathrm{Cl}]_{2} 3 \mathrm{~mol} \%,(R, R, R)-\mathrm{L} 86 \mathrm{~mol} \%$, DABCO 1.0 equiv. THF, $50{ }^{\circ} \mathrm{C}$ then $\mathrm{H}_{3} \mathrm{O}^{+}$

$\mathrm{R}^{1}=\mathrm{H}, \mathrm{R}^{3}=t \mathrm{Bu},\left[\operatorname{Ir}(\operatorname{cod}) \mathrm{Cl}_{2} 3 \mathrm{~mol} \%,(R, R)-\mathrm{L} 66 \mathrm{~mol} \%\right.$, Barton's base 0.2 equiv. DCM, $35{ }^{\circ} \mathrm{C}$ then $\mathrm{H}_{3} \mathrm{O}^{+}$
}

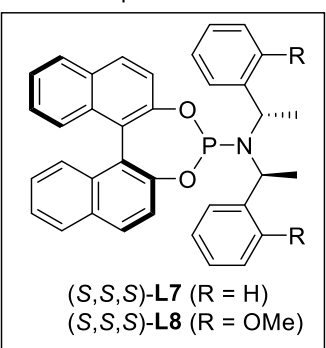

Scheme 26. Ir-catalyzed asymmetric synthesis of $\alpha$-tetrasubstituted $\alpha$-trifluoromethyl homoallylic amines.

Wang's group expanded the Ir-catalyzed tandem asymmetric allylation and aza-Cope rearrangement to the synthesis of chiral homoallylic amines 131 (Scheme 27) [60-62]. With aldimine esters 129 in basic media (Scheme 27a), nucleophilic metalated azomethine ylide 132 and 2-azallyl carbanion 133 were, respectively, formed in the presence and absence of a copper catalyst. These umpolung nucleophiles reacted with the chiral Ir- $\pi$-allyl complex 134, and subsequent aza-Cope rearrangement delivered chiral homoallylic amines 131. With aminomalonates 135 (Scheme 27b), the umpolung nucleophile was also generated under basic conditions, and enantioselective homoallylic amine synthesis was achieved in the same way as above. 
(a) Asymmetric homoallylic amines from aldimin esters

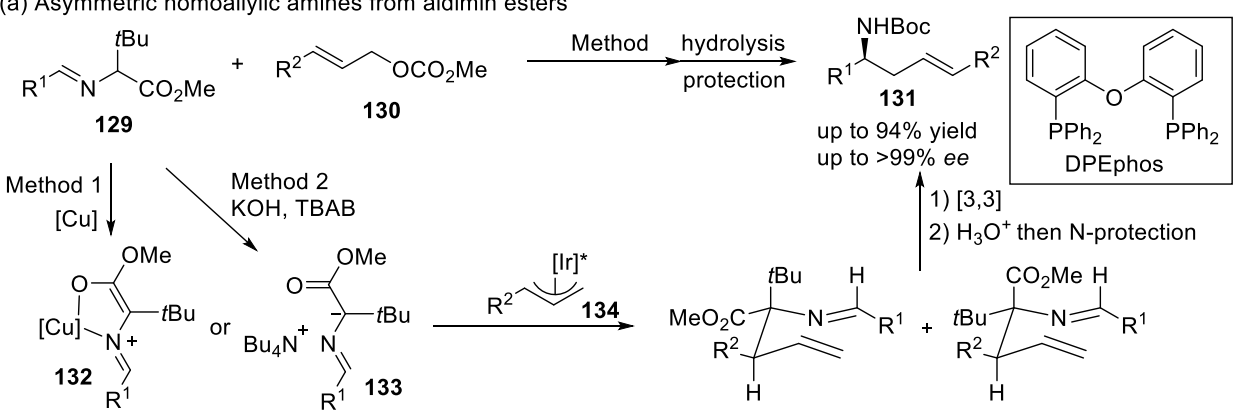

Method 1: Cu(MeCN) ${ }_{4} \mathrm{BF}_{4} 5 \mathrm{~mol} \%$, DPEphos $5.5 \mathrm{~mol} \%$, $[\operatorname{lr}(\operatorname{cod}) \mathrm{Cl}]_{2} 1.5 \mathrm{~mol} \%,(S, S, S)-\mathrm{L} 73 \mathrm{~mol} \%, \mathrm{CsCO}_{3} 1.5$ equiv. $\mathrm{DCM}, 25^{\circ} \mathrm{C}$

Method 2: $[\operatorname{lr}(\operatorname{cod}) \mathrm{Cl}]_{2} 1.5 \mathrm{~mol} \%,(S, S, S)-\mathrm{L} 73 \mathrm{~mol} \%$, TBAB $10 \mathrm{~mol} \%, \mathrm{KOH} 1.5$ equiv., DCM/ $\mathrm{H}_{2} \mathrm{O}$, rt

(b) Asymmetric homoallylic amines from aminomalonates

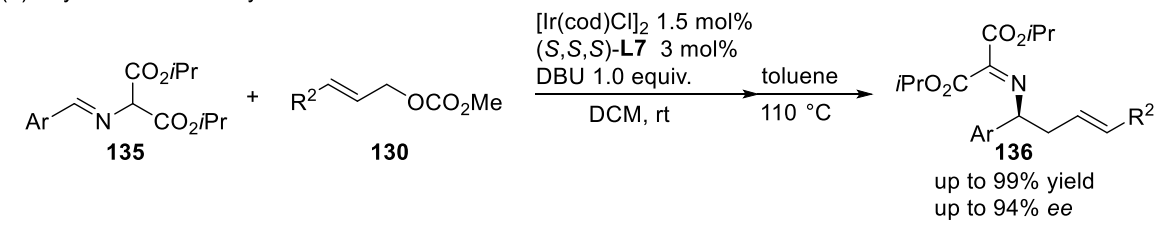

Scheme 27. Ir-catalyzed asymmetric synthesis of homoallylic amines.

Again, considering the $\alpha$-trifluoromethyl chiral quaternary center, Wang and colleagues synthesized asymmetric quaternary $\alpha$-trifluoromethyl $\alpha$-amino acids by Ir-catalyzed allylation [63]. Chiral $\alpha$-trifluoromethyl $\alpha$-to $\varepsilon$-amino acid derivatives 138 were synthesized by Ir-catalyzed cascade allylation and the aza-Cope rearrangement of ketoimine esters 137 (Scheme 28) [64]. The Re-Face asymmetric umpolung allylation of the chiral Ir- $\pi$-allyl complex occurs at either the Re- or Si-face of the ketoimine ester nucleophile to form diastereoisomeric allylation intermediates. The intermediates are converted into the desired amino acid derivatives $\mathbf{1 3 8}$ with high enantioselectivity. When $n$ is not 0 , the Re-Re coupled intermediate cannot undergo the [3,3]-sigmatropic rearrangement due to the increased steric hindrance; thus, the isomerized product 139 is obtained.
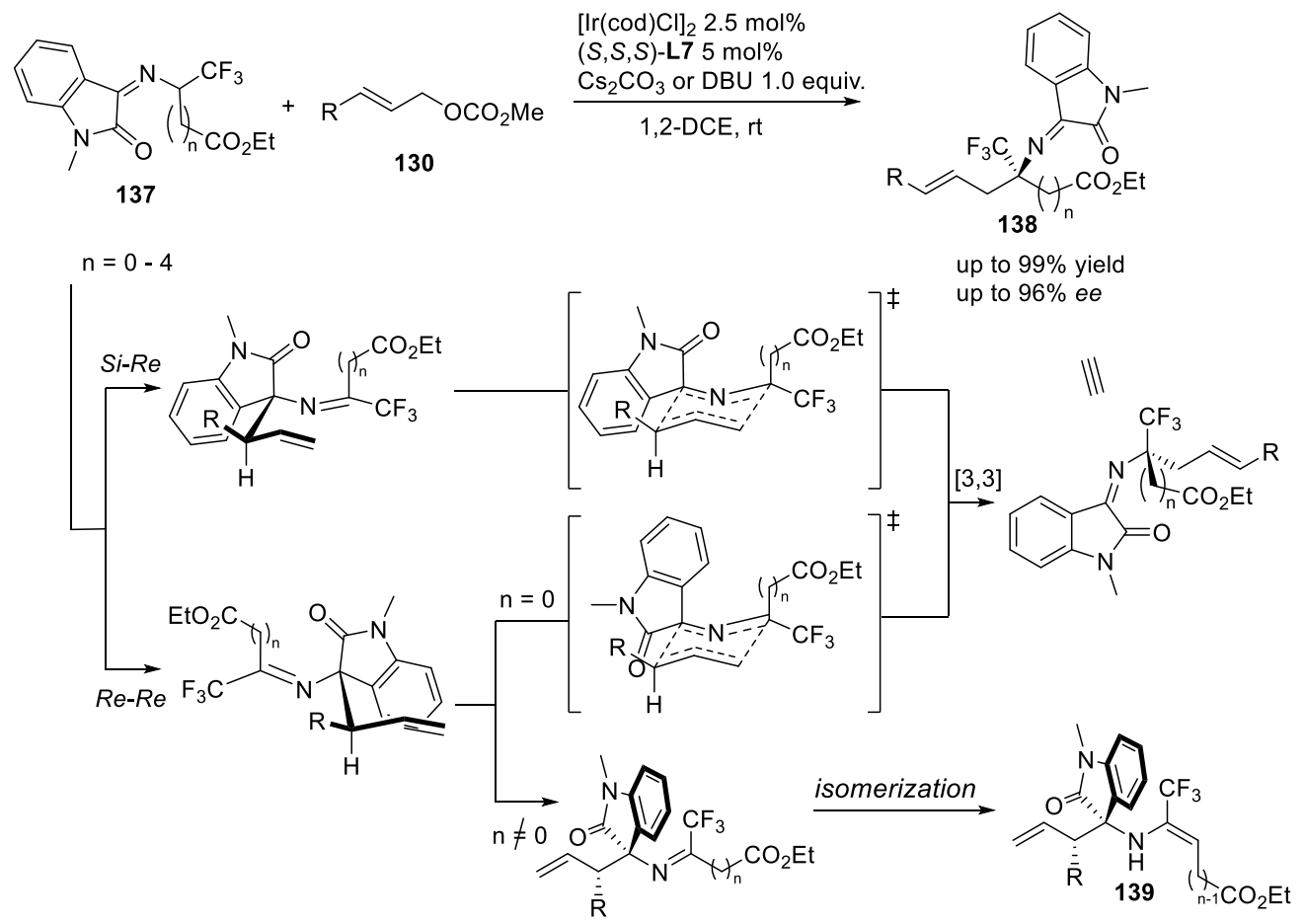

Scheme 28. Ir-catalyzed asymmetric synthesis of $\alpha$-trifluoromethyl amino acid derivatives. 
Using Ir-catalyzed tandem asymmetric allylation and aza-Cope rearrangement, oxazolones and isoxazolinones were subjected to enantioselective and regioselective $\alpha$ alkylation (Scheme 29) [65,66]. With oxazolones 140 (Scheme 29a), asymmetric allylation occurred at the $\alpha$-position, and aza-Cope rearrangement delivered highly enantioenriched oxazolones 142 containing a quaternary carbon center. On the other hand, Nallylation of isoxazolinone 143 with the chiral Ir- $\pi$-allyl complex 146 and subsequent [3,3]sigmatropic rearrangement delivered the chiral quaternary carbon-centered isoxazolinone 145 (Scheme 29b).

(a) With oxazolones

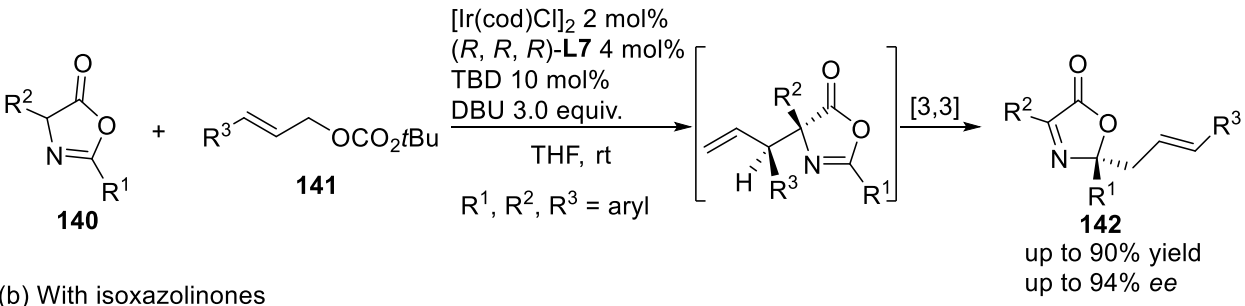

(b) With isoxazolinones

up to $90 \%$ yie
up to $94 \%$ ee

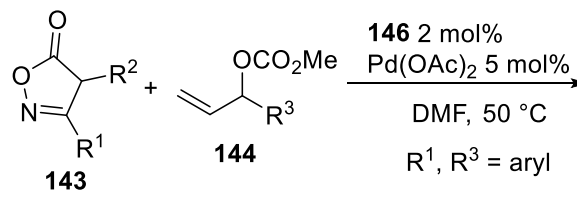
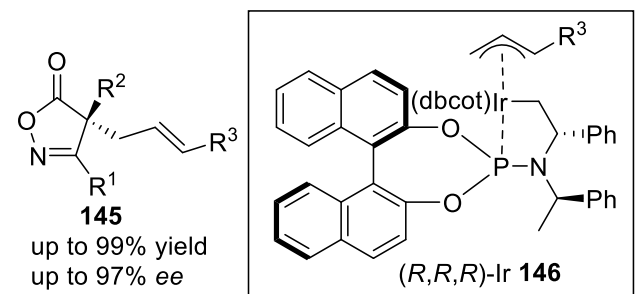

Scheme 29. Ir-catalyzed tandem asymmetric allylic alkylation and aza-Cope rearrangement of oxazolones and isoxazolinones.

Marek's group used Ir-catalyzed Cope rearrangements to produce medium-sized ring structures through ring expansion reactions. In 2019, 7-memebered dienes were synthesized from alkenyl $\omega$-ene cyclopropanes or epoxides 147 via Ir-catalyzed tandem olefin migration and Cope rearrangement (Scheme 30) [67,68]. Migration of the terminal olefin successfully occurred in the presence of a cationic Ir catalyst system to produce 1,5-dienes 148. Subsequent Cope arrangement furnished 7-membered cycles 149 with high diastereoselectivity.

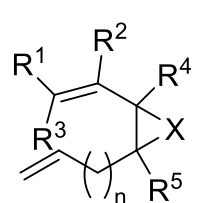

147

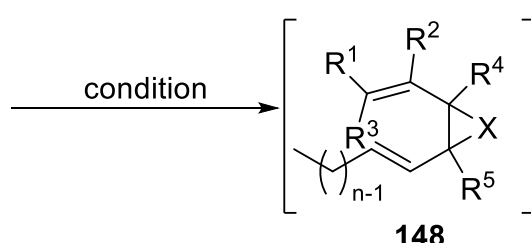

148

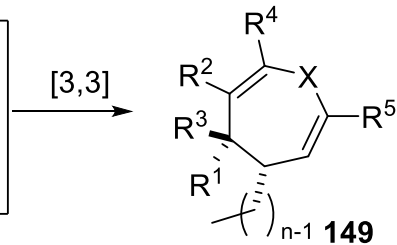

$X=\mathrm{CH}_{2}$ (up to $88 \%$ yield, up to $>20: 1 \mathrm{dr}$ )

$X=O$ (up to $93 \%$ yield, up to $>95: 5 \mathrm{dr}$ )

$\mathrm{X}=\mathrm{CH}_{2}:[\operatorname{Ir}(\operatorname{cod}) \mathrm{Cl}]_{2} 1.0 \mathrm{~mol} \%, \mathrm{NaBArF} 2.5 \mathrm{~mol} \%, \mathrm{PCy}_{3} 6 \mathrm{~mol} \%, 1,2-\mathrm{DCE}, 85^{\circ} \mathrm{C}$ $\mathrm{X}=\mathrm{O}:[\operatorname{Ir}(\operatorname{cod}) \mathrm{Cl}]_{2} 2.0 \mathrm{~mol} \%, \mathrm{NaBArF} 5.0 \mathrm{~mol} \%, \mathrm{PCy}_{3} 6 \mathrm{~mol} \%, \mathrm{PhCl}, 125^{\circ} \mathrm{C}$

Scheme 30. Ir-catalyzed tandem olefin migration and Cope rearrangement for forming 7-membered rings.

Tehrani and colleagues developed the $\mathrm{FeCl}_{3}$-catalyzed synthesis of $\alpha$-substituted homoallylic amines through an aza-Cope rearrangement (Scheme 31) [69]. The Lewis-acid assisted reaction of aldehyde 150 and allyl amine 151 generated the imine 152, which, by a 2 -aza-Cope rearrangement, produced the corresponding $\alpha$-substituted homoallylic amine 152 and regenerated catalyst. This is the first example of Fe-catalyzed 2-aza-Cope rearrangement affording $\alpha$-substituted homoallylic amines 153. 


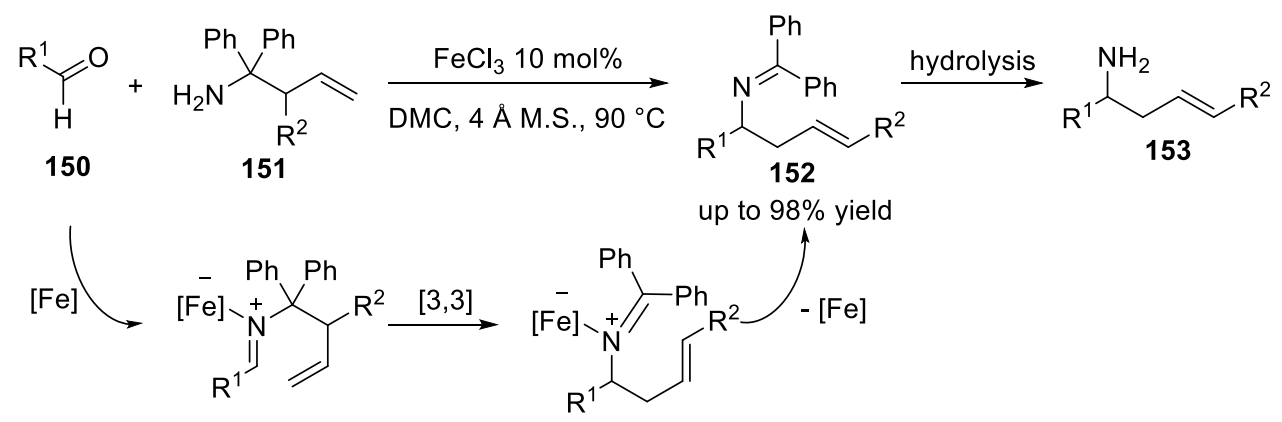

Scheme 31. Fe-catalyzed synthesis of $\alpha$-substituted homoallylic amines.

A bismuth(III)-catalyzed 2-aza-Cope rearrangement was reported into the synthesis of $\alpha$-allyl substituted $\beta$-aminophosphonates 156 from $\alpha$-phosphoryl aldehydes 154 and homoallylic amines 151 (Scheme 32) [70]. The Bi-catalyzed aza-Cope rearrangement of the alkenyl imine intermediate provides the allylic substituted $\beta$-aminophosphonates 155.

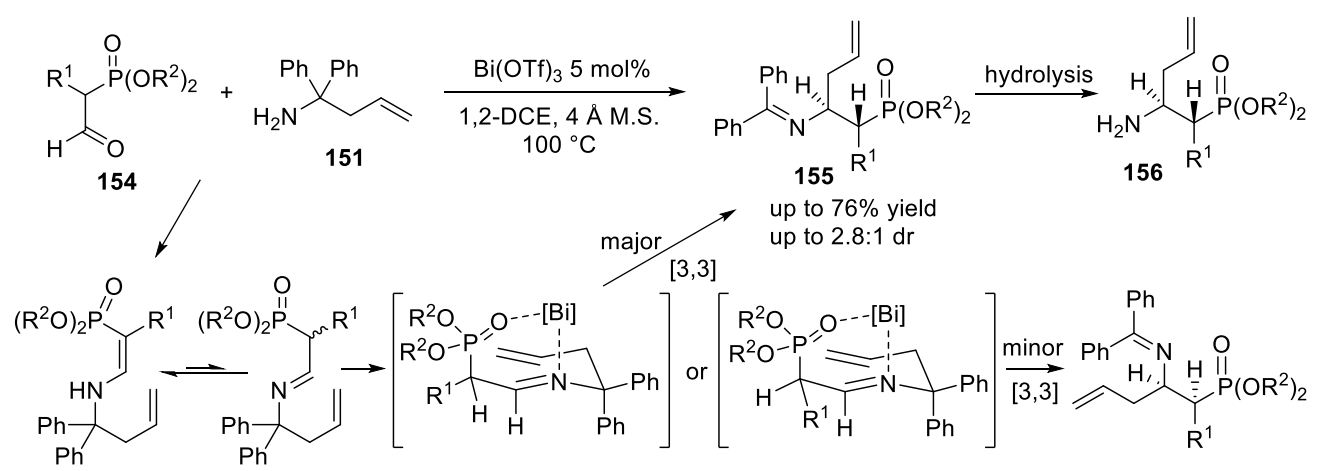

Scheme 32. Bi-catalyzed synthesis of allylic substituted $\beta$-aminophosphonates.

Whereas the tandem 2-aza-Cope-Mannich cyclization reaction is widely used in many natural product syntheses [71], the 3-aza-Cope-Mannich reaction homologous received scarce attention, in spite of the fact that this reaction provides 3-aminocyclopentanones [72]. Sakai's group developed a gold-catalyzed tandem 3-aza-Cope-Mannich cyclization reaction to furnish the fused $N$-heterocycles 158 and $158^{\prime}$ from cyclic tertiary alkynyl amines 157 (Scheme 33) [73]. The [Au]-catalyst activates the alkyne for the $\mathrm{N}$-cyclization to generate the heterocycle 159, which further rearranges to the iminium 160 (3-aza-Cope rearrangement). Finally, the Mannich cyclization creates the tricyclic nitrogen- containing heterocycles 158 and 158'. The total synthesis of (-)-cephalotaxine was accomplished using this methodology.

An indium-catalyzed 2-oxonia-Cope rearrangement was developed into the synthesis of 1,3-dienols 163 from 1,4-dienols 162 (Scheme 34) [74]. 1,4-Dienols 162 were prepared from aldehydes 161 with 5-bromopenta-1,3-diene 164 by indium-mediated addition. Subsequent indium-catalyzed 2-oxonia-Cope rearrangement was initiated by the formation of the oxocarbenium ion 165 by Lewis acid activation of aldehyde 161. Following [3,3]-sigmatropic rearrangement delivered the conjugated diene 166, and 1,3-dienols 163 were obtained by catalyst regeneration. 
(a) Gold-catalyzed tandem cyclization, 3-aza-Cope rearrangement, and Mannich cyclization

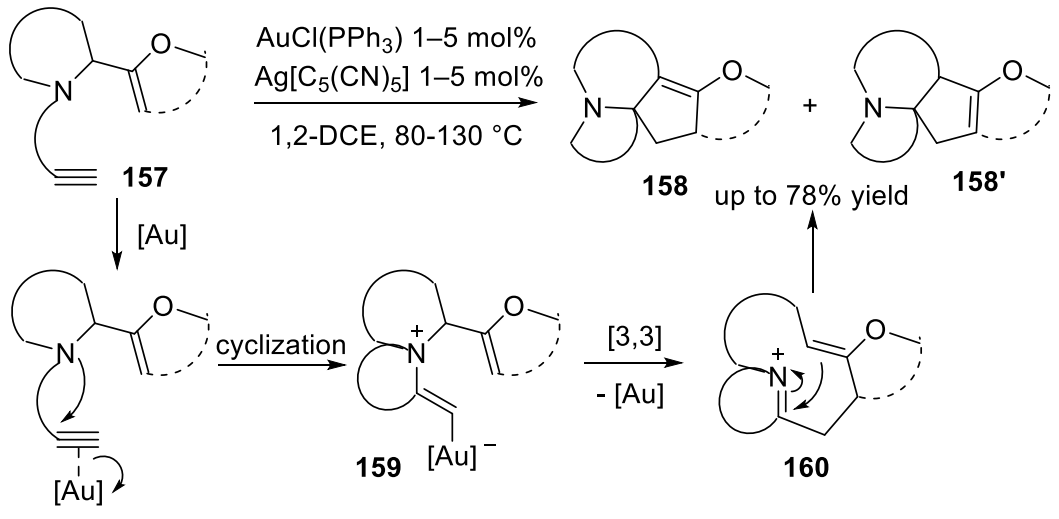

(b) Total synthesis of (-)-cephalotaxine

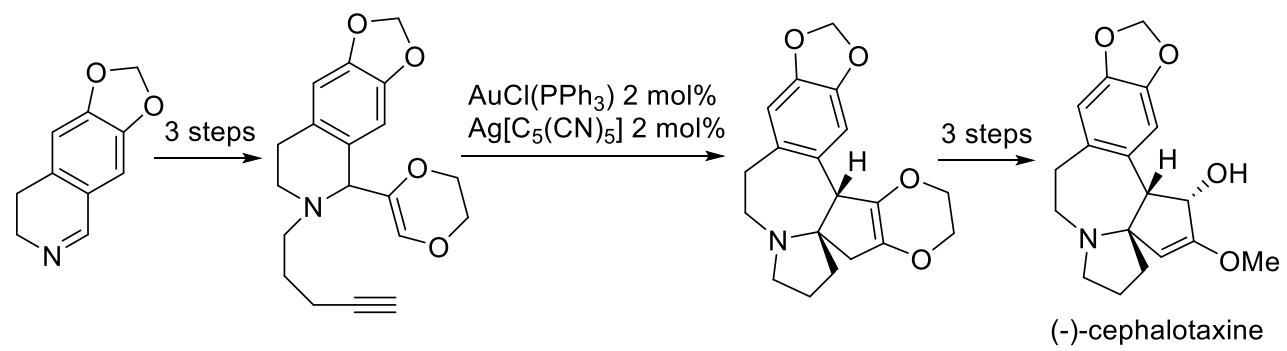

Scheme 33. Synthesis of heterocycles $\mathbf{1 5 8} / \mathbf{1 5 8}^{\prime}$ by gold catalyzed tandem 3-aza-Cope-Mannich cyclization reaction.

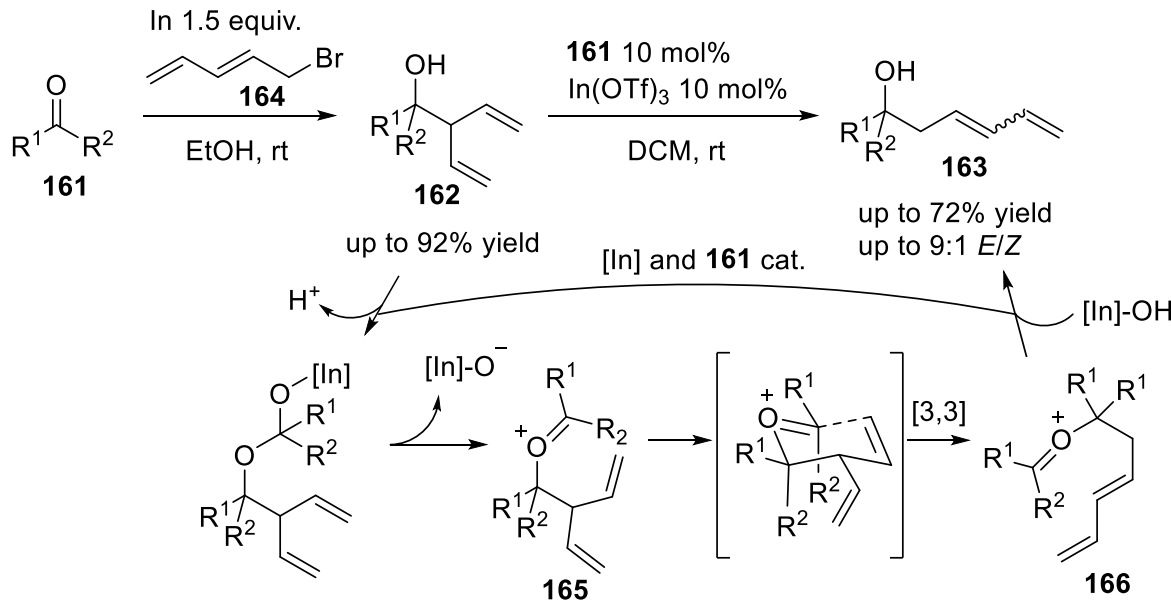

Scheme 34. In-catalyzed synthesis of 1,3-dienols.

\subsection{Organocatalyzed Cope Rearrangement}

The firstly developed organocatalyzed Cope rearrangement was reported in 2016 by the Gleason's group (Scheme 35) [75,76] in the synthesis of $\alpha$-substituted enals 168 from 1,5-hexadienyl-2-carboxyaldehydes 167, using the pair hydrazide 148 / TfOH as the catalyst. The reaction mechanism was elucidated through DFT calculation [77]. The authors found that the 7-membered hydrazide catalyst 169 was ten times more reactive than its 6-membered homologous. Asymmetric Cope rearrangement was demonstrated with the chiral catalyst 172, affording aldehyde $\mathbf{1 7 1}$ in 54\% yield with $47 \%$ ee (Scheme 35b). 
(a) Cyclic hydrazide catalyzed Cope rearrangement

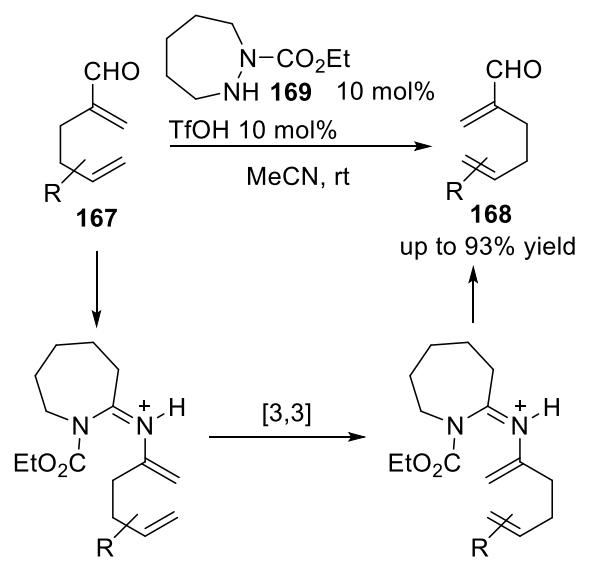

(b) Asymmetric Cope rearrangement with chiral hydrazide catalyst<smiles>C=C(C=O)C(C)(C)C/C=C/Br</smiles><smiles>Cc1ccc(Br)c(C=O)c1</smiles>

Scheme 35. N-Acyl hydrazide-catalyzed Cope rearrangement of 1,5-hexadienyl-2-carboxyaldehydes.

In 2020, Jacobsen's group reported an urea-catalyzed enantiosective anionic oxyCope rearrangement (Scheme 36) [78]. The authors attempted to elucidate the reaction mechanism by testing various reaction conditions using structurally different catalysts and additives. The bifunctional urea catalyst $\mathbf{1 7 3}$ cooperatively promoted the rearrangement by $\mathrm{H}$-bonding and cation-binding. Additionally, large charge separation between the reacting oxyanion and its counteraction is required.

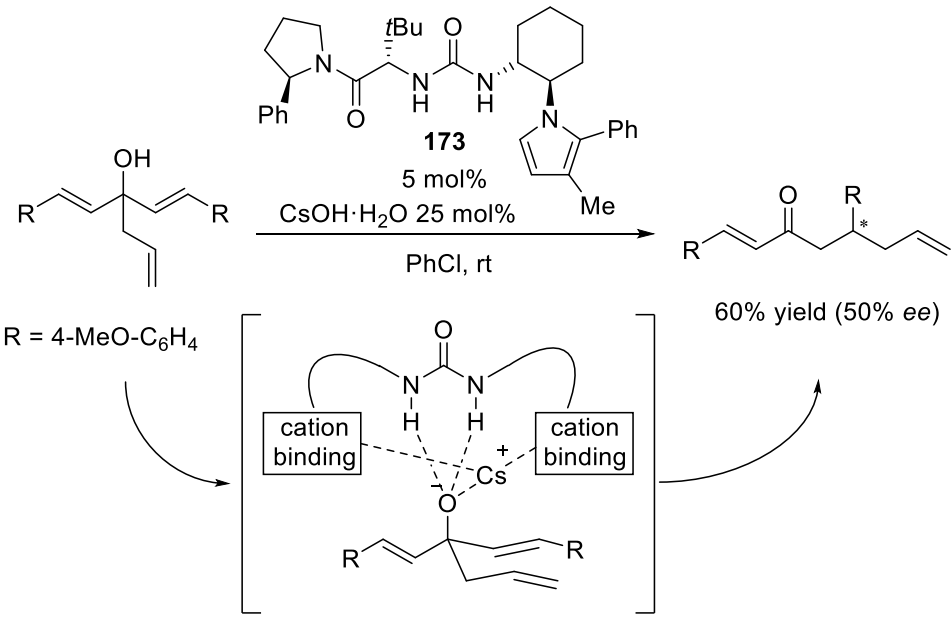

Scheme 36. Urea-catalyzed enantioselective anionic oxy-Cope rearrangement.

In 2018, Han's group developed a highly stereoselective 2-oxonia-Cope rearrangement for the vinylogous aldol reactions of aldehydes (Scheme 37) [79,80]. From the stereo-defined homoallylic alcohols 174 and 178, the oxocarbenium ion 176 and $\mathbf{1 7 6}$ ' $^{\prime}$ were generated by Lewis acid activated aldehydes. Following 2-oxonia-Cope rearrangement, stereoselectively delivered the product-side oxocarbenium ion 177 and $177^{\prime}$ by reducing the steric repulsion of the initial oxocarbenium ion 176 and $\mathbf{1 7 6}^{\prime}$. Using this methodology, 5-hydroxy-2,3unsaturated carbonyl compounds 175 and $\varepsilon$-hydroxy- $\alpha, \beta, \gamma, \delta$-unsaturated esters 179 were obtained with excellent regio-, enantio-, and diastereoselectivity. 
(a) Lewis acid-mediated stereoselective vinylogous aldol reaction of aldehydes

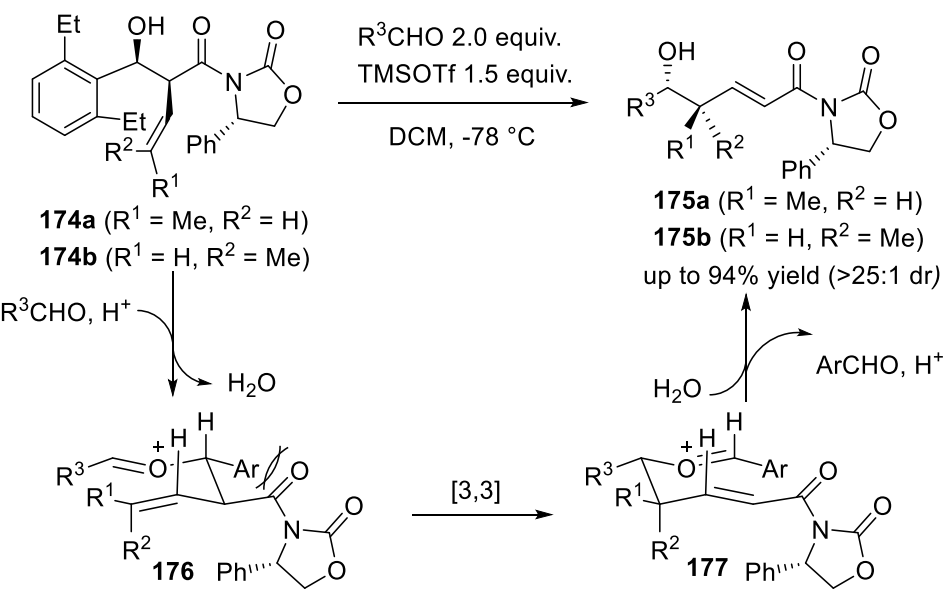

(b) Lewis acid-mediated asymmetric bisvinylogous aldolation of aldehydes

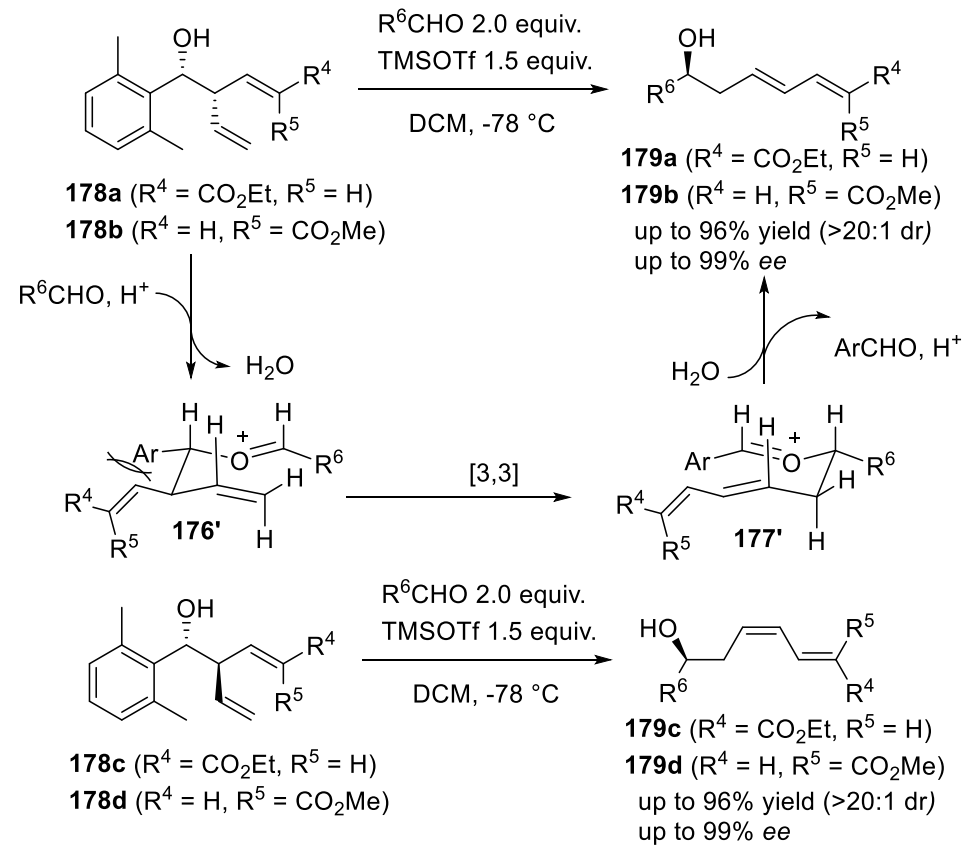

Scheme 37. TMSOTf-mediated stereoselective vinylogous aldol reactions via 2-oxonia-Cope rearrangement.

\section{Conclusions and Outlooks}

This review summarizes the recently developed catalyzed [3,3]-sigmatropic rearrangement reactions. After the first discovery of the Claisen rearrangement by L. Claisen in 1912 and the Cope rearrangement by A. C. Cope in 1940, various syntheses were achieved. Based on this powerful [3,3]-sigmatropic rearrangement, unique carbon-carbon bond formation reactions were developed using transition metals or small organic compounds for the catalytic reactions.

Various transition metals were significantly studied for the Claisen and Cope rearrangement reactions with various substrate types. Not only the first-row transition metals, but also the second-row transition metals were utilized in the reactions to achieve improved reactivity and selectivity. Notably, the combination of transition metal and chiral ligands for catalysis allowed enantioselectivity in the reaction. The lanthanides were also applied to catalytic rearrangement reactions, especially Sc, Y, and Eu.

Organocatalysts are good alternatives to avoid the environmental and economic issues associated with the use of metal-containing catalysts, where various reactions have been intensively studied, including Brønsted acid catalysis, Brønsted base catalysis, Lewis base 
catalysis, and Lewis acid catalysis. The chiral environment of the small organic molecular catalyst is transferred into the rearrangement reaction to achieve asymmetric synthesis. In the case of organocatalysis for the Cope rearrangement, both hydrazides and ureas were representatively studied.

In spite of the recent breakthroughs in catalytic [3,3]-sigmatropic rearrangement, heavy metal catalyzed reactions are still dominant, and the development of more sustainable methodologies is required. Enhancing the efficiency and selectivity by metal-free catalysis can boost the synthetic utility of these reactions and application fields. Organocatalyzed photoredox-induced reactions, an emerging field in organic synthesis, may expand cascade reactions involving [3,3]-sigmatropic rearrangement to afford highly functionalized and fused cyclic compounds with excellent enantioselectivity.

Author Contributions: H.L. and C.K. designed and conceptualized the main story line for the manuscript. H.L., K.T.K. and C.K. summarized and categorized transition metal catalyzed reaction. M.K. summarized and categorized the organocatalyzed reactions. All authors prepared and wrote the manuscript together. All authors have read and agreed to the published version of the manuscript.

Funding: This project was supported by the Basic Science Research Program (NRF-2020R1F1A1067981 for H.L. and C.K.) through the National Research Foundation of Korea (NRF) funded by the Ministry of Science and ICT.

Conflicts of Interest: The authors declare no conflict of interest.

\section{References}

1. Claisen, L. Über Umlagerung von Phenol-allyläthern in C-Allyl-phenole. Chem. Ber. 1912, 45, 3157-3166. [CrossRef]

2. Ito, H.; Taguchi, T. Asymmetric Claisen rearrangement. Chem. Soc. Rev. 1999, 28, 43-50. [CrossRef]

3. Martín Castro, A.M. Claisen Rearrangement over the Past Nine Decades. Chem. Rev. 2004, 104, 2939-3002. [CrossRef] [PubMed]

4. Ilardi, E.A.; Stivala, C.E.; Zakarian, A. [3,3]-Sigmatropic rearrangements: Recent applications in the total synthesis of natural products. Chem. Soc. Rev. 2009, 38, 3133-3148. [CrossRef]

5. Tejedor, D.; Méndez-Abt, G.; Cotos, L.; García-Tellado, F. Propargyl Claisen rearrangement: Allene synthesis and beyond. Chem. Soc. Rev. 2013, 42, 458-471. [CrossRef]

6. Domingo, L.R.; Ríos-Gutiérrez, M.; Chamorro, E.; Pérez, P. Aromaticity in Pericyclic Transition State Structures? A Critical Rationalisation Based on the Topological Analysis of Electron Density. ChemistrySelect 2016, 1, 6026-6039. [CrossRef]

7. Domingo, L.R.; Ríos-Gutiérrez, M.; Silvi, B.; Pérez, P. The Mysticism of Pericyclic Reactions: A Contemporary Rationalisation of Organic Reactivity Based on Electron Density Analysis. Eur. J. Org. Chem. 2018, 2018, 1107-1120. [CrossRef]

8. Cope, A.C.; Hardy, E.M. The Introduction of Substituted Vinyl Groups. V. A Rearrangement Involving the Migration of an Allyl Group in a Three-Carbon System1. J. Am. Chem. Soc. 1940, 62, 441-444. [CrossRef]

9. Lutz, R.P. Catalysis of the Cope and Claisen rearrangements. Chem. Rev. 1984, 84, 205-247. [CrossRef]

10. Blechert, S. The Hetero-Cope Rearrangement in Organic Synthesis. Synthesis 1989, 1989, 71-82. [CrossRef]

11. Graulich, N. The Cope rearrangement-the first born of a great family. WIREs Comput. Mol. Sci. 2011, 1, 172-190. [CrossRef]

12. Kotha, S.; Meshram, M. Application of Claisen Rearrangement and Olefin Metathesis in Organic Synthesis. Chem. Asian. J. 2018, 13, 1758-1766. [CrossRef] [PubMed]

13. Shi, C.-Y.; Li, L.; Kang, W.; Zheng, Y.-X.; Ye, L.-W. Claisen rearrangement triggered by transition metal-catalyzed alkyne alkoxylation. Coord. Chem. Rev. 2021, 446, 214131. [CrossRef]

14. Wei, L.; Wang, C.-J. Recent advances in catalytic asymmetric aza-Cope rearrangement. Chem. Commun. 2021, 57, 10469-10483. [CrossRef] [PubMed]

15. Tomiczek, B.M.; Grenning, A.J. Aromatic Cope rearrangements. Org. Biomol. Chem. 2021, 19, 2385-2398. [CrossRef]

16. Liu, Y.; Liu, X.; Hu, H.; Guo, J.; Xia, Y.; Lin, L.; Feng, X. Synergistic Kinetic Resolution and Asymmetric Propargyl Claisen Rearrangement for the Synthesis of Chiral Allenes. Angew. Chem. Int. Ed. 2016, 55, 4054-4058. [CrossRef]

17. Liu, Y.; Hu, H.; Lin, L.; Hao, X.; Liu, X.; Feng, X. Enantioselective construction of branched 1,3-dienyl substituted quaternary carbon stereocenters by asymmetric allenyl Claisen rearrangement. Chem. Commun. 2016, 52, 11963-11966. [CrossRef]

18. Zheng, H.; Wang, Y.; Xu, C.; Xu, X.; Lin, L.; Liu, X.; Feng, X. Stereodivergent synthesis of vicinal quaternary-quaternary stereocenters and bioactive hyperolactones. Nat. Commun. 2018, 9, 1968. [CrossRef]

19. Ireland, R.E.; Mueller, R.H. Claisen rearrangement of allyl esters. J. Am. Chem. Soc. 1972, 94, 5897-5898. [CrossRef]

20. Ireland, R.E.; Mueller, R.H.; Willard, A.K. The ester enolate Claisen rearrangement. Stereochemical control through stereoselective enolate formation. J. Am. Chem. Soc. 1976, 98, 2868-2877. [CrossRef]

21. Wong, K.C.; Ng, E.; Wong, W.-T.; Chiu, P. Copper Hydride Catalyzed Reductive Claisen Rearrangements. Chem. Eur. J. 2016, 22, 3709-3712. [CrossRef] [PubMed] 
22. Miller, S.P.; Morken, J.P. Catalytic Diastereoselective Reductive Claisen Rearrangement. Org. Lett. 2002, 4, 2743-2745. [CrossRef] [PubMed]

23. Guo, S.; Wong, K.C.; Scheeff, S.; He, Z.; Chan, W.T.K.; Low, K.-H.; Chiu, P. Copper-Catalyzed Reductive Ireland-Claisen Rearrangements of Propargylic Acrylates and Allylic Allenoates. J. Org. Chem. 2022, 87, 429-452. [CrossRef] [PubMed]

24. Yan, X.; Liu, H.; Wei, S.; Huang, H. Catalytic Claisen Rearrangement by Intercepting Ketenimines with Propargylic Alcohols: A Strategy to Generate and Transform Ketenimines from Radicals. Org. Lett. 2020, 22, 6794-6798. [CrossRef]

25. Zhou, B.; Li, L.; Zhu, X.-Q.; Yan, J.-Z.; Guo, Y.-L.; Ye, L.-W. Yttrium-Catalyzed Intramolecular Hydroalkoxylation/Claisen Rearrangement Sequence: Efficient Synthesis of Medium-Sized Lactams. Angew. Chem. Int. Ed. 2017, 56, 4015-4019. [CrossRef] [PubMed]

26. Zhou, B.; Li, L.; Liu, X.; Tan, T.-D.; Liu, J.; Ye, L.-W. Yttrium-Catalyzed Tandem Intermolecular Hydroalkoxylation/Claisen Rearrangement. J. Org. Chem. 2017, 82, 10149-10157. [CrossRef]

27. Ramadhar, T.R.; Kawakami, J.-I.; Batey, R.A. Sequential O-Arylation/Lanthanide(III)-Catalyzed [3,3]-Sigmatropic Rearrangement of Bromo-Substituted Allylic Alcohols. Synlett 2017, 28, 2865-2870. [CrossRef]

28. Lai, Z.-W.; Liu, C.; Sun, H.; You, S.-L. Asymmetric Synthesis of 3-Allyloxindoles and 3-Allenyloxindoles by Scandium(III)Catalyzed Claisen Rearrangement Reactions. Chin. J. Chem. 2017, 35, 1512-1516. [CrossRef]

29. Zhang, C.; Zhen, L.; Yao, Z.; Jiang, L. Iron(III)-Catalyzed Domino Claisen Rearrangement/Regio- and Chemoselective Aerobic Dehydrogenative Cyclization of $\beta$-Naphthyl-Substituted-Allenylmethyl Ether. Org. Lett. 2019, 21, 955-959. [CrossRef]

30. Wang, H.; Li, T.; Zheng, Z.; Zhang, L. Efficient Synthesis of $\alpha$-Allylbutenolides from Allyl Ynoates via Tandem Ligand-Enabled $\mathrm{Au}(\mathrm{I})$ Catalysis and the Claisen Rearrangement. ACS Catal. 2019, 9, 10339-10342. [CrossRef]

31. Li, J.; Lin, L.; Hu, B.; Zhou, P.; Huang, T.; Liu, X.; Feng, X. Gold(I)/Chiral N,N'-Dioxide-Nickel(II) Relay Catalysis for Asymmetric Tandem Intermolecular Hydroalkoxylation/Claisen Rearrangement. Angew. Chem. Int. Ed. 2017, 56, 885-888. [CrossRef] [PubMed]

32. Chen, Y.; Dong, S.; Xu, X.; Liu, X.; Feng, X. Bimetallic Rhodium(II)/Indium(III) Relay Catalysis for Tandem Insertion/Asymmetric Claisen Rearrangement. Angew. Chem. Int. Ed. 2018, 57, 16554-16558. [CrossRef] [PubMed]

33. Majumdar, K.C.; Pal, A.K. Lewis acid catalyzed Claisen rearrangement: Regioselective synthesis of oxygen, nitrogen, and sulfur heterocycles. Can. J. Chem. 2008, 86, 72-78. [CrossRef]

34. Uyeda, C.; Jacobsen, E.N. Enantioselective Claisen Rearrangements with a Hydrogen-Bond Donor Catalyst. J. Am. Chem. Soc. 2008, 130, 9228-9229. [CrossRef] [PubMed]

35. Wenzel, A.G.; Jacobsen, E.N. Asymmetric Catalytic Mannich Reactions Catalyzed by Urea Derivatives: Enantioselective Synthesis of $\beta$-Aryl- $\beta$-Amino Acids. J. Am. Chem. Soc. 2002, 124, 12964-12965. [CrossRef]

36. Salvio, R. The Guanidinium Unit in the Catalysis of Phosphoryl Transfer Reactions: From Molecular Spacers to Nanostructured Supports. Chem. Eur. J. 2015, 21, 10960-10971. [CrossRef]

37. Leow, D.; Tan, C.-H. Catalytic Reactions of Chiral Guanidines and Guanidinium Salts. Synlett 2010, 2010, 1589-1605. [CrossRef]

38. Seo, H.-S.; Kim, H.-J. Guanidinium-based Organocatalyst for $\mathrm{CO}_{2}$ Utilization under Mild Conditions. Bull. Korean Chem. Soc. 2019, 40, 169-172. [CrossRef]

39. Kaeobamrung, J.; Mahatthananchai, J.; Zheng, P.; Bode, J.W. An Enantioselective Claisen Rearrangement Catalyzed by NHeterocyclic Carbenes. J. Am. Chem. Soc. 2010, 132, 8810-8812. [CrossRef]

40. Vedachalam, S.; Murugesh, N.; Chakraborty, P.; Karvembu, R.; Liu, X.-W. NHC catalyzed enantioselective Coates-Claisen rearrangement: A rapid access to the dihydropyran core for oleuropein based secoiridoids. New J. Chem. 2018, 42, 1832-1839. [CrossRef]

41. Dzieszkowski, K.; Barańska, I.; Rafiński, Z. Construction of Dihydropyrido[2,3-d]pyrimidine Scaffolds via Aza-Claisen Rearrangement Catalyzed by N-Heterocyclic Carbenes. J. Org. Chem. 2020, 85, 6645-6662. [CrossRef]

42. Li, L.; Zhu, X.-Q.; Zhang, Y.-Q.; Bu, H.-Z.; Yuan, P.; Chen, J.; Su, J.; Deng, X.; Ye, L.-W. Metal-free alkene carbooxygenation following tandem intramolecular alkoxylation/Claisen rearrangement: Stereocontrolled access to bridged [4.2.1] lactones. Chem. Sci. 2019, 10, 3123-3129. [CrossRef] [PubMed]

43. Chen, P.-F.; Zhou, B.; Wu, P.; Wang, B.; Ye, L.-W. Brønsted Acid Catalyzed Dearomatization by Intramolecular Hydroalkoxylation/Claisen Rearrangement: Diastereo- and Enantioselective Synthesis of Spirolactams. Angew. Chem. Int. Ed. 2021, 60, 27164-27170. [CrossRef] [PubMed]

44. Miró, J.; Gensch, T.; Ellwart, M.; Han, S.-J.; Lin, H.-H.; Sigman, M.S.; Toste, F.D. Enantioselective Allenoate-Claisen Rearrangement Using Chiral Phosphate Catalysts. J. Am. Chem. Soc. 2020, 142, 6390-6399. [CrossRef] [PubMed]

45. Reed, J.H.; Donets, P.A.; Miaskiewicz, S.; Cramer, N. A 1,3,2-Diazaphospholene-Catalyzed Reductive Claisen Rearrangement. Angew. Chem. Int. Ed. 2019, 58, 8893-8897. [CrossRef] [PubMed]

46. Sun, Z.; Li, Z.; Liao, W.-W. An organocatalytic hydroalkoxylation/Claisen rearrangement/Michael addition tandem sequence: Divergent synthesis of multi-substituted 2,3-dihydrofurans and 2,3-dihydropyrroles from cyanohydrins. Green Chem. 2019, 21, 1614-1618. [CrossRef]

47. Kleinmans, R.; Will, L.E.; Schwarz, J.L.; Glorius, F. Photoredox-enabled 1,2-dialkylation of $\alpha$-substituted acrylates via IrelandClaisen rearrangement. Chem. Sci. 2021, 12, 2816-2822. [CrossRef] 
48. Sakai, N.; Enomoto, K.; Takayanagi, M.; Konakahara, T.; Ogiwara, Y. Copper-catalyzed [3+2] annulation of propargylic acetates with anilines in the presence of trimethylsilyl chloride leading to 2,3-disubstituted indoles via an aza-Claisen rearrangement. Tetrahedron Lett. 2016, 57, 2175-2178. [CrossRef]

49. Wang, C.-G.; Wu, R.; Li, T.-P.; Jia, T.; Li, Y.; Fang, D.; Chen, X.; Gao, Y.; Ni, H.-L.; Hu, P.; et al. Copper(I)-Catalyzed Ketenimine Formation/Aza-Claisen Rearrangement Cascade for Stereoselective Synthesis of $\alpha$-Allylic Amidines. Org. Lett. 2020, 22, 3234-3238. [CrossRef]

50. Bae, I.; Han, H.; Chang, S. Highly Efficient One-Pot Synthesis of N-Sulfonylamidines by Cu-Catalyzed Three-Component Coupling of Sulfonyl Azide, Alkyne, and Amine. J. Am. Chem. Soc. 2005, 127, 2038-2039. [CrossRef]

51. Yoo, E.J.; Ahlquist, M.; Bae, I.; Sharpless, K.B.; Fokin, V.V.; Chang, S. Mechanistic Studies on the Cu-Catalyzed Three-Component Reactions of Sulfonyl Azides, 1-Alkynes and Amines, Alcohols, or Water: Dichotomy via a Common Pathway. J. Org. Chem. 2008, 73, 5520-5528. [CrossRef] [PubMed]

52. Kljajic, M.; Puschnig, J.G.; Weber, H.; Breinbauer, R. Additive-Free Pd-Catalyzed $\alpha$-Allylation of Imine-Containing Heterocycles. Org. Lett. 2017, 19, 126-129. [CrossRef] [PubMed]

53. Alexander, J.R.; Cook, M.J. Formation of Ketenimines via the Palladium-Catalyzed Decarboxylative $\pi$-Allylic Rearrangement of N-Alloc Ynamides. Org. Lett. 2017, 19, 5822-5825. [CrossRef] [PubMed]

54. Alexander, J.R.; Shchepetkina, V.I.; Stankevich, K.S.; Benedict, R.J.; Bernhard, S.P.; Dreiling, R.J.; Cook, M.J. Pd-Catalyzed Rearrangement of N-Alloc-N-allyl Ynamides via Auto-Tandem Catalysis: Evidence for Reversible C-N Activation and Pd(0)Accelerated Ketenimine Aza-Claisen Rearrangement. Org. Lett. 2021, 23, 559-564. [CrossRef]

55. Verlee, A.; Heugebaert, T.; van der Meer, T.; Kerchev, P.; Van Breusegem, F.; Stevens, C.V. Domino reaction of a gold catalyzed 5-endo-dig cyclization and a [3,3]-sigmatropic rearrangement towards polysubstituted pyrazoles. Org. Biomol. Chem. 2018, 16, 9359-9363. [CrossRef]

56. Yang, W.; Lin, X.; Zhang, Y.; Cao, W.; Liu, X.; Feng, X. Nickel(ii)-catalyzed asymmetric thio-Claisen rearrangement of $\alpha$-diazo pyrazoleamides with thioindoles. Chem. Commun. 2020, 56, 10002-10005. [CrossRef]

57. Liu, W.-B.; Okamoto, N.; Alexy, E.J.; Hong, A.Y.; Tran, K.; Stoltz, B.M. Enantioselective $\gamma$-Alkylation of $\alpha$, $\beta$-Unsaturated Malonates and Ketoesters by a Sequential Ir-Catalyzed Asymmetric Allylic Alkylation/Cope Rearrangement. J. Am. Chem. Soc. 2016, 138, 5234-5237. [CrossRef]

58. Shen, C.; Wang, R.-Q.; Wei, L.; Wang, Z.-F.; Tao, H.-Y.; Wang, C.-J. Catalytic Asymmetric Umpolung Allylation/2-Aza-Cope Rearrangement for the Construction of $\alpha$-Tetrasubstituted $\alpha$-Trifluoromethyl Homoallylic Amines. Org. Lett. 2019, 21, 6940-6945. [CrossRef]

59. Wang, Y.; Deng, L.-F.; Zhang, X.; Niu, D. Catalytic Asymmetric Synthesis of $\alpha$-Tetrasubstituted $\alpha$-Trifluoromethyl Homoallylic Amines by Ir-Catalyzed Umpolung Allylation of Imines. Org. Lett. 2019, 21, 6951-6956. [CrossRef]

60. Wei, L.; Zhu, Q.; Xiao, L.; Tao, H.-Y.; Wang, C.-J. Synergistic catalysis for cascade allylation and 2-aza-cope rearrangement of azomethine ylides. Nat. Commun. 2019, 10, 1594. [CrossRef]

61. Wei, L.; Xiao, L.; Wang, Z.-F.; Tao, H.-Y.; Wang, C.-J. Ir/Phase-Transfer-Catalysis Cooperatively Catalyzed Asymmetric Cascade Allylation/2-aza-Cope Rearrangement: An Efficient Route to Homoallylic Amines from Aldimine Esters. Chin. J. Chem. 2020, 38, 82-86. [CrossRef]

62. Wang, R.-Q.; Shen, C.; Cheng, X.; Wang, Z.-F.; Tao, H.-Y.; Dong, X.-Q.; Wang, C.-J. Sequential Ir-Catalyzed Allylation/2-aza-Cope Rearrangement Strategy for the Construction of Chiral Homoallylic Amines. Chin. J. Chem. 2020, 38, 807-811. [CrossRef]

63. Sun, X.-S.; Ou-Yang, Q.; Xu, S.-M.; Wang, X.-H.; Tao, H.-Y.; Chung, L.W.; Wang, C.-J. Asymmetric synthesis of quaternary $\alpha$-trifluoromethyl $\alpha$-amino acids by Ir-catalyzed allylation followed by kinetic resolution. Chem. Commun. 2020, 56, 3333-3336. [CrossRef] [PubMed]

64. Sun, X.-S.; Wang, X.-H.; Tao, H.-Y.; Wei, L.; Wang, C.-J. Catalytic asymmetric synthesis of quaternary trifluoromethyl $\alpha$ - to $\varepsilon$-amino acid derivatives via umpolung allylation/2-aza-Cope rearrangement. Chem. Sci. 2020, 11, 10984-10990. [CrossRef]

65. Bai, X.-D.; Zhang, Q.-F.; He, Y. Enantioselective iridium catalyzed $\alpha$-alkylation of azlactones by a tandem asymmetric allylic alkylation/aza-Cope rearrangement. Chem. Commun. 2019, 55, 5547-5550. [CrossRef]

66. Rieckhoff, S.; Meisner, J.; Kästner, J.; Frey, W.; Peters, R. Double Regioselective Asymmetric C-Allylation of Isoxazolinones: Iridium-Catalyzed N-Allylation Followed by an Aza-Cope Rearrangement. Angew. Chem. Int. Ed. 2018, 57, 1404-1408. [CrossRef]

67. Sommer, H.; Weissbrod, T.; Marek, I. A Tandem Iridium-Catalyzed "Chain-Walking" /Cope Rearrangement Sequence. ACS Catal. 2019, 9, 2400-2406. [CrossRef]

68. Suresh, R.; Massad, I.; Marek, I. Stereoselective tandem iridium-catalyzed alkene isomerization-cope rearrangement of $\omega$-diene epoxides: Efficient access to acyclic 1,6-dicarbonyl compounds. Chem. Sci. 2021, 12, 9328-9332. [CrossRef]

69. Gadde, K.; Daelemans, J.; Maes, B.U.W.; Abbaspour Tehrani, K. Lewis acidic $\mathrm{FeCl}_{3}$ promoted 2-aza-Cope rearrangement to afford $\alpha$-substituted homoallylamines in dimethyl carbonate. RSC Adv. 2019, 9, 18013-18017. [CrossRef]

70. Jin, M.; Yin, S.-f.; Yang, S.-D. Bismuth(III)-Catalyzed Sequential Enamine-Imine Tautomerism/2-Aza-Cope Rearrangement of Stable $\beta$-Enaminophosphonates: One-Pot Synthesis of $\beta$-Aminophosphonates. Org. Lett. 2020, 22, 2811-2815. [CrossRef]

71. Mailyan, A.K.; Eickhoff, J.A.; Minakova, A.S.; Gu, Z.; Lu, P.; Zakarian, A. Cutting-Edge and Time-Honored Strategies for Stereoselective Construction of C-N Bonds in Total Synthesis. Chem. Rev. 2016, 116, 4441-4557. [CrossRef] [PubMed] 
72. Kuhn, C.; Le Gouadec, G.; Skaltsounis, A.L.; Florent, J.C. Synthesis of chiral 4-alkyl 4-hydroxy cyclopentenones via a diastereoselective tandem aza-Cope/Mannich cyclization reaction from aldehydosugar. Tetrahedron Lett. 1995, 36, 3137-3140. [CrossRef]

73. Sakai, T.; Okumura, C.; Futamura, M.; Noda, N.; Nagae, A.; Kitamoto, C.; Kamiya, M.; Mori, Y. Gold(I)-Catalyzed Cyclization-3Aza-Cope-Mannich Cascade and Its Application to the Synthesis of Cephalotaxine. Org. Lett. 2021, 23, 4391-4395. [CrossRef] [PubMed]

74. Capel, N.J.; Lindley, M.R.; Pritchard, G.J.; Kimber, M.C. Indium-Mediated 2-Oxonia Cope Rearrangement of 1,4-Dienols to 1,3-Dienols. ACS Omega 2019, 4, 785-792. [CrossRef]

75. Kaldre, D.; Gleason, J.L. An Organocatalytic Cope Rearrangement. Angew. Chem. Int. Ed. 2016, 55, 11557-11561. [CrossRef]

76. Gebauer, K.; Schneider, C. The First Organocatalytic Cope Rearrangement. Angew. Chem. Int. Ed. 2016, 55, 14208-14209. [CrossRef]

77. Sanders, J.N.; Jun, H.; Yu, R.A.; Gleason, J.L.; Houk, K.N. Mechanism of an Organocatalytic Cope Rearrangement Involving Iminium Intermediates: Elucidating the Role of Catalyst Ring Size. J. Am. Chem. Soc. 2020, 142, 16877-16886. [CrossRef]

78. Kennedy, C.R.; Choi, B.Y.; Reeves, M.-G.R.; Jacobsen, E.N. Enantioselective Catalysis of an Anionic Oxy-Cope Rearrangement Enabled by Synergistic Ion Binding. Isr. J. Chem. 2020, 60, 461-474. [CrossRef]

79. Padarti, A.; Kim, D.; Han, H. Highly Stereoselective 2-Oxonia-Cope Rearrangement: A Platform Enabling At-Will Control of Regio-, Enantio-, and Diastereoselectivity in the Vinylogous Aldol Reactions of Aldehydes. Org. Lett. 2018, 20, 756-759. [CrossRef]

80. Woody, D.; Padarti, A.; Han, H. Asymmetric Bisvinylogous Aldolation of Aldehydes via 2-Oxonia-Cope Rearrangement Enabling Total Stereochemical Control. Org. Lett. 2018, 20, 2472-2476. [CrossRef] 